\title{
Thyroid hormones deficiency impairs male germ cell development: a cross talk between hypothalamic-pituitary-thyroid, and - gonadal axes in zebrafish
}

\author{
1 Maira S Rodrigues ${ }^{1,2 \&}$, Aldo Tovo-Neto ${ }^{1,2 \&}$, Ivana F da Rosa ${ }^{2}$, Lucas B Doretto ${ }^{2}$, Hamideh P \\ 2 Fallah $^{3}$, Hamid R Habibi ${ }^{3}$, Rafael H Nóbrega ${ }^{2^{*}}$ \\ $3 \quad{ }^{1}$ Aquaculture Program (CAUNESP), São Paulo State University (UNESP), 14884-900, Jaboticabal, \\ 4 São Paulo, Brazil \\ ${ }^{2}$ Reproductive and Molecular Biology Group, Department of Structural and Functional Biology, \\ Institute of Biosciences, São Paulo State University (UNESP), 18618-970, Botucatu, São Paulo, \\ 8 Brazil \\ ${ }^{3}$ Department of Biological Sciences, University of Calgary, 500 University Drive NW, Calgary, \\ Alberta, T2N 1N4, Canada
}

\section{* Correspondence:}

14 Corresponding Author

15 Dr. Rafael Henrique Nóbrega

16 Contact: +55 (14) 3880-0482

17 Email address: rafael.nobrega@unesp.br

${ }^{\&}$ These authors contributed equally to this work

Total Word Count: 11430

Keywords: hypothyroidism, methimazole, thyroid hormones, spermatogenesis, zebrafish

Abstract

In vertebrates, thyroid hormones, including thyroxine (T4) and triiodothyronine (T3), are critical players in controlling different physiological processes such as development, growth, metabolism among others. There is evidence in mammals that thyroid hormones are also an important component of the hormonal system that controls reproduction, although studies in fish remain poorly investigated. Here we tested this hypothesis by investigating the effects of methimazole-induced hypothyroidism on the testicular function in adult $D$. rerio. Treatment of fish with methimazole, in vivo, significantly affected the progression of zebrafish spermatogenesis by inducing the accumulation of pre-meiotic cells, delaying cell differentiation and meiosis, as well as reducing the number of spermatozoa. The observed impairment of spermatogenesis by methimazole was correlated with significant changes in transcript levels for several genes involved in the control of reproduction. Using an in vitro approach, we also demonstrated that in addition to affecting the 


\section{Thyroid hormones deficiency impairs male germ cell development: a cross talk between hypothalamic-pituitary-thyroid, and - gonadal axes in zebrafish}

components of the brain-pituitary-peripheral axis, $\mathrm{T} 3$ also exerts direct action at the level of the testis. These results support the hypothesis that thyroid hormones are an essential component of multifactorial control of reproduction and testicular function in zebrafish and possibly other vertebrates.

\section{Introduction}

The production of thyroid hormones in fish and other vertebrates is under the control of the hypothalamic-pituitary-thyroid (HPT) axis (Cooke et al., 1994; Tousson et al., 2011; DuarteGuterman et al., 2014; Kang et al., 2020). The thyrotropin (TSH)-releasing factor [thyrotropinreleasing hormone (TRH)/corticotropin-releasing hormone $(\mathrm{CRH})]$ stimulates the anterior pituitary to release TSH, which in turn, promotes the synthesis and release of thyroid hormones, including T4 and T3, by thyroid follicles (Larsen et al., 1998). Of the two, T3 is the more biologically active thyroid hormone owing to its affinity for the nuclear thyroid hormone receptor (Carr and Patiño, 2011). The HPT axis acts parallel to the hypothalamic-pituitary-gonadal (HPG) axis, which involves a large number of hormones, including the gonadotropin-releasing hormone $(\mathrm{GnRH})$ that stimulates the secretion of gonadotropin hormones, luteinizing hormone (LH), and follicle-stimulating hormone (FSH) (Schulz et al., 2010; Pankhurst, 2016) which are crucial for testis development and spermatogenesis in fish (Schulz et al., 2010; for a review see Xie et al., 2020). There is evidence for interaction between HPT and HPG axes in vertebrates (Teerds et al., 1998; Ariyaratne et al., 2000; Matta et al., 2002; Wagner et al., 2009; Morais et al., 2013; Kang et al., 2020), although this subject remains poorly investigated in fish, particularly, in the male reproductive system (Habibi et al., 2012; Castañeda-Cortés et al., 2014; Tovo-Neto et al., 2018; Ma et al., 2020a, b). In mammals, it has been shown that $\mathrm{T} 3$ regulates the growth and maturation of testis by inhibiting immature Sertoli cell proliferation and stimulating their terminal differentiation (Cooke and Meisami, 1991; Hess et al., 1993; Cooke et al., 1994). Furthermore, in postnatal rat testis, an important action of thyroid hormones is to initiate the onset of Leydig cell differentiation and stimulation of steroidogenesis (Ariyaratne et al., 2000), in part, by increasing the expression of steroidogenic acute regulatory protein (StAR) (Mendis-Handagama and Ariyaratne, 2005). The presence of thyroid hormone receptors in the mammalian testis, particularly in Leydig cells, suggests both direct and indirect actions of thyroid hormones on testicular function (Hernandez, 2018). The regulatory role of thyroid hormones is complex, species specific, and dependent on developmental stages. Neonatal hypothyroidism was shown to impair testicular growth and sperm production in rats (França et al., 1995), hamsters (Mesocricetus auratus) (Jansen et al., 2007), and juvenile teleost fish (Oreochromis niloticus) (Matta et al., 2002).

A number of researchers have investigated the role of thyroid hormones in fish embryogenesis, larval development, and growth (Blanton and Specker, 2007; Mukhi et al., 2007; Orozco et al., 2012). With regards to fish male reproduction, there are some evidence that thyroid hormones can affect spermatogenesis (Cyr and Eales, 1996; Wagner et al., 2009; Nelson et al., 2010; Habibi et al., 2012; Morais et al., 2013; Safian et al., 2016; Tovo-Neto et al, 2018). In adult catfish, Clarias gariepinus, treatment with thiourea (a thyroid disruptor) reduced 11-ketostestosterone (11-KT) and testosterone (T) production (Swapna et al., 2006), leading to male reproductive system disruption. Morais and collaborators (2013) demonstrated the influence of thyroid hormones on zebrafish spermatogenesis using an ex vivo approach. In the same study, the authors showed that T3 stimulated the increase in mitotic index of type $A$ undifferentiated spermatogonia $\left(\mathrm{A}_{\text {und }}\right)$ and Sertoli cells through Igf3 (Insulin-like growth factor like 3), a Sertoli cell stimulatory growth factor (Morais et al., 2013). Moreover, the same authors showed that T3 potentiated FSH actions on steroid release and enhanced Fsh-stimulated cyp17al (17 $\alpha$-hydroxylase/17,20 lyase) and ar mRNA levels in zebrafish 
bioRxiv preprint doi: https://doi.org/10.1101/2022.01.30.478377; this version posted January $30,2022$. The copyright holder for this preprint (which was not certified by peer review) is the author/funder, who has granted bioRxiv a license to display the preprint in perpetuity. It is made available under aCC-BY-NC-ND 4.0 International license.

\section{Thyroid hormones deficiency impairs male germ cell development: a cross talk between hypothalamic-pituitary-thyroid, and - gonadal axes in zebrafish}

testis (Morais et al., 2013). There is also evidence that thyroid hormones interact with other reproductive peptides such as GnRH and gonadotropin-inhibitory hormones $(\mathrm{GnIH})$ in vivo (Ma et al., 2020a, b) and in vitro in the zebrafish testis (Rodrigues et al., 2021). Other studies have demonstrated that GnRH stimulates thyroid activity in a freshwater murrel, Channa gachua, and two carp species, Catla catla and Cirrhinus mrigala (Roy et al., 2000). GnRH injection increases plasma T4 levels in different vertebrate species (Jacobs et al., 1988; Roy et al., 2000; Chiba et al., 2004), suggesting an effect of endogenous pituitary gonadotropin release due the heterothyrotropic activities of GnRH on the thyroid (Mackenzie, 1982, 1987). In general, these findings support the hypothesis that normal thyroid hormone action is critical for HPG axis function and normal gonadal function. However, significant gaps remain regarding exact physiological significance of thyroid hormones on fish male reproductive function.

The aim of this study was to further investigate the influence of thyroid hormones on male zebrafish (D. rerio) reproduction using in vivo and ex vivo approaches. We first evaluated the effect of hypothyroidism induced by methimazole and co-treatment with $\mathrm{T} 4$ on zebrafish spermatogenesis by histomorphometrical measurement and measured testicular transcript levels for genes related to reproduction, as well as 11-KT plasma levels and basal and FSH-induced 11-KT release in vitro. Subsequently, we investigated the effects of hypothyroidism induced by methimazole treatment and T3 injection, on zebrafish brain and pituitary by transcript measurement. Finally, we investigated long-term effects of T3 on zebrafish spermatogenesis by histomorphometrical analysis, and transcript levels of a selected genes. The results provide a framework for better understanding of the role of thyroid hormone in the control of male reproduction in zebrafish.

\section{Methods}

\subsection{Animals}

Sexually mature male zebrafish (4-5-months-old) were bred and raised in the aquarium facility of the Department of Structural and Functional Biology, Institute of Biosciences, Botucatu, São Paulo State University (UNESP). The animals were kept in 6-L tanks in the recirculating system under constant temperature conditions, similar to the natural environment $\left(28^{\circ} \mathrm{C}\right)$, and proper photothermal conditions (14-h light/10-h dark). $\mathrm{pH}$, salinity, dissolved oxygen, and ammonia were monitored in all tanks every other day. Fish were fed twice a day with commercial food (Sera Vipan Flakes $^{\circledR}$ ). Handling and experimentation were performed according to the Brazilian legislation regulated by National Council for the Control of Animal Experimental (CONCEA) and Ethical Principles in Animal Research (Protocol n. 1031-CEUA) and University of Calgary animal care committee and in accordance with the guidelines of the Canadian Council of Animal Care (Protocol \#AC19-0161).

\subsection{Treatment solutions: methimazole-induced hypothyroidism and reversal treatment with T4}

A solution of methimazole (1-methyl-3H-imidazole-2-thione) (CAS 60-56-0; MW, 114.17 $\mathrm{g} / \mathrm{mol}$; purity, $\geq 99 \%$; Sigma-Aldrich) was used to induce hypothyroidism. A stock solution of methimazole was prepared by dissolving $11.4 \mathrm{~g}$ of methimazole in $1000 \mathrm{~mL}$ of distilled water. Exposure concentration of $1 \mathrm{mM}$ was prepared by mixing $10 \mathrm{~mL}$ of the stock solution per liter of water in the tank. A stock solution (1 mg/mL) of T4 (CAS 51-48-9; MW, $776.87 \mathrm{~g} / \mathrm{mol}$; SigmaAldrich) was prepared by dissolving $1 \mathrm{mg}$ of T4 in $1 \mathrm{~mL}$ of DMSO (dimethyl sulfoxide; CAS 67-685 ; MW, $78.13 \mathrm{~g} / \mathrm{mol}$; Vetec), and a treatment solution of $100 \mu \mathrm{g} / \mathrm{L}$ was prepared by adding $100 \mu \mathrm{L}$ of 


\section{Thyroid hormones deficiency impairs male germ cell development: a cross talk between hypothalamic-pituitary-thyroid, and - gonadal axes in zebrafish}

\section{1}

the stock solution per liter of reconstituted water. To avoid problems while adding a new variable, the same amount of DMSO was added in all the tanks. Two thirds of the water volume was replaced every day (i.e., semi-static aquatic exposure). The working concentration of methimazole $(1 \mathrm{mM})$ and T4 $(100 \mu \mathrm{g} / \mathrm{L})$ were selected based on previous studies (Sharma and Patiño, 2013; Sharma et al., 2016; Rodrigues et al., 2021). In this study, adult male zebrafish $(\mathrm{n}=144)$ were divided into four replicate tanks per experimental group: control [only filtered water $(\mathrm{n}=36)$ ]; group I [filtered water with T4 $(100 \mu \mathrm{g} / \mathrm{L})(\mathrm{n}=36)$ ]; group II [filtered water with methimazole $(1 \mathrm{mM})(\mathrm{n}=36)$ ]; group III [1 mM of methimazole followed by addition of T4 $(100 \mu \mathrm{g} / \mathrm{L})(\mathrm{n}=36)$ as reversal treatment group (methimazole $+\mathrm{T} 4)]$. In the T4 group (group I), males were exposed to reconstituted water containing $100 \mu \mathrm{g} / \mathrm{L}$ of T4 from the second week until the end of treatment. In the methimazole group (group II), adult males were exposed to reconstituted water containing $1 \mathrm{mM}$ methimazole for 3 weeks. Also, the reversal treatment (methimazole + T4) group (group III), males were exposed to reconstituted water containing $1 \mathrm{mM}$ methimazole for 3 weeks, and T4 $(100 \mu \mathrm{g} / \mathrm{L})$ was added in the water from the second week until the end of treatment. The reversal treatment with $\mathrm{T} 4$ was performed to address whether the effects observed were a direct effect of the lowering/removal of thyroid hormones. The experimental groups were euthanized by overdose with benzocaine hydrochloride $(250 \mathrm{mg})$ previously dissolved in ethanol and then mixed with water. After euthanasia, the heads (control, methimazole and methimazole $+\mathrm{T} 4$ ) were collected for histological analysis of the thyroid follicles, while the testes from control, methimazole, and methimazole $+\mathrm{T} 4$ groups were dissected and immediately used for in vivo experiments (histomorphometric analysis and gene expression); androgen plasma levels and ex vivo organ culture experiment [short-term $(18 \mathrm{~h})$ incubation for androgen release by zebrafish testicular explants] were available on the treatments (control, T4, methimazole and methimazole $+\mathrm{T} 4$ groups) (see below). The brain and pituitary from the control and methimazole groups were collected for gene expression (see below).

\subsection{Thyroid follicles histology}

Thyroid follicles from control, methimazole and methimazole $+\mathrm{T} 4$ groups were examined histologically. Thyroid follicles appear dispersed among the afferent branchial arterioles (Patinõ et a., 2003; Van der Ven et al., 2006). Head was separated from the trunk, dissected, and fixed in modified Karnovsky (2\% glutaraldehyde and 4\% paraformaldehyde in Sorensen buffer [0.1 M, pH 7.2]) for at least $24 \mathrm{~h}$ at room temperature. After, samples were dehydrated, embedded in Technovit (7100) historesin (Heraeus Kulzer, Wehrheim, Germany), and serial sections at 3- $\mu$ m thickness were obtained and stained with $0.1 \%$ toluidine blue in $1 \%$ sodium borate, according to conventional histological procedures. Then, histological sections were examined and documented using a Leica DMI6000 microscope.

\subsection{Histomorphometrical evaluation of zebrafish spermatogenesis}

After adult zebrafish were exposed to methimazole and methimazole + T4, testes $(n=8$ per treatment) were dissected and immediately fixed in $4 \%$ Karnovsky fixative at $4{ }^{\circ} \mathrm{C}$ overnight, dehydrated, embedded in Technovit (7100) historesin (Heraeus Kulzer, Wehrheim, Germany), sectioned at $3-\mu \mathrm{m}$ thickness, and stained with $0.1 \%$ toluidine blue, according to conventional histological procedures. The slides were evaluated, and the proportion of section surface area of spermatogenic cysts containing type $A$ undifferentiated spermatogonia $\left(A_{\text {und* }}\right.$ and $\left.A_{\text {und }}\right)$, type $A$ differentiated spermatogonia ( $\mathrm{A}_{\text {diff }}$ ), type B spermatogonia $(\mathrm{SpgB})$, spermatocytes $(\mathrm{Spc})$, and 
bioRxiv preprint doi: https://doi.org/10.1101/2022.01.30.478377; this version posted January $30,2022$. The copyright holder for this preprint (which was not certified by peer review) is the author/funder, who has granted bioRxiv a license to display the preprint in perpetuity. It is made available under aCC-BY-NC-ND 4.0 International license.

\section{Thyroid hormones deficiency impairs male germ cell development: a cross talk between hypothalamic-pituitary-thyroid, and - gonadal axes in zebrafish}

spermatids (Spt) were determined. Intersection points were counted on the histologic fields, for which five fields per slide $(n=8$ slides per treatment $)$ were quantified using a grid of $540(54 \times 10)$ intersections under 100x objective lens. The proportion of section area occupied by different germ cell types were represented as fold-change of control value.

The relative number of spermatozoa per area was quantified for each treatment. Twenty different fields were captured from a 100x objective lens and analyzed by IMAGEJ Software (available at http://imagej.nih.gov/ij/index.html) for quantification of spermatozoa number according to Fallah et al., (2019, 2020), Tovo-Neto et al., (2020) and Rodrigues et al., (2021). This software allows quantification of several types of cells by limiting the size of the particle. First, it is necessary to defocus the image, and this filter may avoid false positive cells and improve the measurement. Next, threshold feature is activated, which separates the background comprising unspecific particles of interest. Then, the RGB image is converted into gray scale picture ( 8 or 16 bytes), and the threshold allows for lower intensity signals to be white and higher intensity signals to be black. The algorithm (for analyzing particles) can be applied for measuring black particles in the range of prefixed size.

\subsection{Transcript analysis by quantitative real-time PCR (qPCR)}

Total RNA from testes (control, methimazole, and methimazole + T4 groups) was extracted using TRIzolTM (Invitrogen, Carlsbad, CA, USA), according to the manufacturer's instructions, and quantity and purity were checked with a NanoDrop ${ }^{\mathrm{TM}}$ One Spectrophotometer (Thermo Scientific, Madison, WI, USA). cDNA synthesis was performed as described previously (Nóbrega et al., 2010). qPCR reactions were conducted using $5 \mu \mathrm{L}$ of $2 \mathrm{x}$ SYBR-Green Universal Master Mix, $1 \mu \mathrm{L}$ of forward primer $(9 \mathrm{mM}), 1 \mu \mathrm{L}$ of reverse primer $(9 \mathrm{mM}), 0.5 \mu \mathrm{L}$ of DEPC water, and $2.5 \mu \mathrm{L}$ of cDNA. The relative mRNA levels of $t h r \alpha$ and $t h r \beta$ (thyroid hormone receptors), $f s h r$ (folliclestimulating hormone receptor), cyp17al (17 $\alpha$-hydroxylase/17,20 lyase/17,20 desmolase), insl3 (insulin-like peptide 3), cx43 (testicular connexin), igf3 (insulin-like growth factor 3), amh (antiMüllerian hormone), gsdf (gonadal somatic cell derived factor), nanos 2 (marker of undifferentiated spermatogonia), dazl (deleted in azoospermia-like), sycp3l (synaptonemal complex protein 3) and $o d f 3 a$ (outer dense fiber protein 3 ) were measured in the different treatments.

Brain $(n=8)$ and pituitary $(n=4$ pools of 4 pituitaries for each pool) were collected from control and methimazole groups. Brain of each fish was kept separate. Total RNA was extracted from the brain using TRIzol ${ }^{\mathrm{TM}}$ (Invitrogen, Carlsbad, CA, USA) method. At least four pituitary glands were pooled per group ( $\mathrm{n}=4$ pools per treatment), and total RNA was extracted using a commercial kit (PureLink ${ }^{\mathrm{TM}}$ RNAMini Kit, Ambion, Life Technologies, Carlsbad, CA, USA). After RNA extraction, the usual downstream procedures were followed according to methods described above. The relative mRNA levels of gnrh2 and gnrh3 (gonadotropin-releasing hormones), gnih (gonadotropin-inhibitory hormone), and $\operatorname{crf}$ (corticotropin-releasing hormone) were evaluated in the brain, and the $l h b$ (luteinizing hormone), $f s h b$ (follicle-stimulating hormone), and tsh (thyroidstimulating hormone) mRNA levels were determined in the pituitary gland. mRNA levels of the targets (Cts) were normalized by the reference gene $\beta$-actin and expressed as relative values of the control group (as fold induction) according to the $2^{-(\Delta \Delta \mathrm{Ct})}$ method. Primers were designed based on zebrafish sequences available at Genbank (NCBI) (Table 1).

\subsection{Quantification of androgen (11-KT) plasma levels}




\section{Thyroid hormones deficiency impairs male germ cell development: a cross talk between hypothalamic-pituitary-thyroid, and - gonadal axes in zebrafish}

Blood from adult male fish in different conditions (control, T4, methimazole, and methimazole $+T 4$ groups) were collected ( $n=8$ per condition). Fish were euthanized, and the caudal peduncle was cut for blood sampling using heparinized syringes and tubes. Samples were centrifuged at $4^{\circ} \mathrm{C}$ for $10 \mathrm{~min}$ at $800 \times \mathrm{g}$ (Eppendorf Centrifuge $\left.5424 \mathrm{R}\right)$, and 11-Ketotestosterone (11-KT) plasma levels were quantified by ELISA (582751, Cayman Chemical), following the manufacturer's instructions. The results were evaluated as nanograms of 11-KT per milliliter of plasma.

\subsection{Testis tissue culture}

Testes were dissected and cultured using an ex vivo organ culture system described previously (Leal et al., 2009). For short-term incubations (18 h for 11-KT release analysis), testes were submerged in a culture medium, whereas for long-term exposure ( 7 days for histomorphometrical analysis and gene expression), testes were placed on a nitrocellulose membrane on top of a cylinder of agarosis and exposed to $1 \mathrm{~mL}$ of medium culture in 24-well flat-bottom plates, as described by Leal and collaborators (2009).

\subsection{Short-term $(\mathbf{1 8} \mathrm{h})$ incubation}

Testes were collected from eight animals per condition (control, T4, methimazole, methimazole + T4) post-dissection. One testis was cultivated in the Lebovitz medium (L-15), whereas its contra-lateral one in L-15 containing recombinant zebrafish Fsh (rzfFsh; $100 \mathrm{ng} / \mathrm{mL}$ ). Testes were incubated in 96-well plates containing $200 \mu \mathrm{L}$ of solution in each well at $28^{\circ} \mathrm{C}$. Following incubation, testes were individually weighed, and the medium was collected and stored at $-20{ }^{\circ} \mathrm{C}$ for androgen release (11-KT) assay (see sub-section 2.9).

\section{9 in vitro 11-KT release by zebrafish testicular explants in short-term incubation}

This technique was used to examine if treatment conditions (T4, methimazole, methimazole + T4) modulated rzfFsh (100 ng/mL)-induced androgen release by zebrafish testis. The androgen (11Ketostesterone, 11-KT) release capacity of zebrafish testicular tissue into culture medium was measured after a short-term (18 h) ex vivo culture system as described previously (García-López et al., 2010). The levels of 11-KT released in the culture medium were quantified by ELISA using a commercial kit (Cayman Chemical) following manufacturer's instructions.

\subsection{Long-term (7 days) incubation}

To study the effects of $\mathrm{T} 3(100 \mathrm{nM} / \mathrm{mL})(\mathrm{n}=8)$ on zebrafish spermatogenesis, long-term incubations were performed. For that, each testis was placed on a nitrocellulose membrane measuring $0.25 \mathrm{~cm}^{2}(25 \mu \mathrm{m}$ of thickness and $0.22 \mu \mathrm{m}$ of porosity) on top of a cylinder of agarose $(1.5 \% \mathrm{w} / \mathrm{v}$, Ringer's solution, $\mathrm{pH} 7.4$ ) with $1 \mathrm{~mL}$ of culture medium into a 24 -well plate. One testis was incubated in the presence of T3 alone and its contralateral one in a basal culture medium. The medium was changed every 3 days. After 7 days, testes were collected for histomorphometrical analysis. The proportion of section area occupied by different germ cell types were represented as fold-change of basal value. The relative number of spermatozoa per area was quantified as described 


\section{Thyroid hormones deficiency impairs male germ cell development: a cross talk between hypothalamic-pituitary-thyroid, and - gonadal axes in zebrafish}

above (see sub-section 2.4). Also, this technique was used to analyze if different concentrations of T3 and T4 $(10,100$ and $1000 \mathrm{nM} / \mathrm{mL})$ modulate expression of selected genes in zebrafish testis. For that testis were collected, total RNA was extracted from testis explants $(\mathrm{n}=8)$ and the relative mRNA levels of nanos 2 , sycp $3 l, 3 \beta$-HSD (3-beta ( $\beta$ )-hydroxysteroid dehydrogenase), and cyp17al were evaluated as described above (see sub-section 2.5) (Table 1).

\subsection{T3 injections}

Adult zebrafish males were intracoelomically injected with 0 and $250 \mathrm{ng}$ of T3 per fish $(\mathrm{n}=$ 16). The dose was selected based on their ability to induce deiodinase type 3 transcript as described previously (Nelson and Habibi, 2008; Nelson et al., 2010). First, a stock solution of T3 was prepared in $0.02 \mathrm{M}$ sodium hydroxide and diluted in physiologic saline. The control group was injected with a vehicle (only physiologic saline solution). After twelve hours, the animals were euthanized, and brain and pituitary glands were collected. Brain of each fish $(\mathrm{n}=8)$ was kept separate. The pituitaries were pooled in groups of four per group ( $\mathrm{n}=4$ pools of 4 pituitaries per condition) for RNA extraction. mRNA release levels of gnrh2 and gnrh3, gnih, and $c r f$ were measured in the brain, and $l h b, f s h b$, and $t s h$ were measured from pituitary glands (Table 1). RNA extraction and downstream procedures were followed as previously described in sub-section 2.5.

\subsection{Statistical analysis}

All data were subjected to normality Shapiro-Wilk test, which was followed by the Bartlett homogeneity variance test. Significant differences were identified using unpaired or paired t-tests for two groups or one-way ANOVA followed by the Student-Newman-Keuls or Dunnett's tests for three or more groups. Significance level $(p)$ was considered at 0.05 in both cases. Data are presented as mean \pm SEM (Standard Error of Mean). All data analysis was performed by Graph Pad Prism software 7.04 (Graph Pad Software, Inc., San Diego, CA, USA, http://www.graphpad.com).

\section{Results}

\subsection{Thyroid follicles analysis}

Thyroid gland follicles were examined histologically in the control group and following treatments with methimazole and methimazole + T4 (Fig. 1(A)-(D)). The control group thyroid follicles consisted of squamous/cuboidal epithelial cells filled with colloid (Fig. 1(B)). The results demonstrate a significant change in the histological condition of thyroid follicles in fish treated with methimazole. Three-week exposure to $1 \mathrm{mM}$ methimazole resulted in follicles with columnar epithelium, follicle cell hypertrophy, and colloid depletion (Fig. 1(C)). These morphological changes were consistent with studies in which zebrafish were exposed to methimazole (Rodrigues et al., 2021), and other goitrogens, such as 6-n-propyl-2-thiouracil (PTU) (Van der Ven et al., 2006) and perchlorate (Patiño et al., 2003). The observed effect of methimazole was reversed by co-treatment with T4, in which the thyroid follicles were found to be morphologically similar to the control group (Fig. 1(D)). The results demonstrate that methimazole-induced hypothyroidism in zebrafish had altered thyroid function following treatment with the goitrogen. Also, the results demonstrate that cotreatment with $\mathrm{T} 4$ restored the zebrafish thyroid follicular structure. 
bioRxiv preprint doi: https://doi.org/10.1101/2022.01.30.478377; this version posted January $30,2022$. The copyright holder for this preprint (which was not certified by peer review) is the author/funder, who has granted bioRxiv a license to display the preprint in perpetuity. It is made available under aCC-BY-NC-ND 4.0 International license.

Thyroid hormones deficiency impairs male germ cell development: a cross talk between hypothalamic-pituitary-thyroid, and - gonadal axes in zebrafish

\subsection{Methimazole-induced hypothyroidism and reversal treatment with T4: histomorphometrical analysis of the zebrafish testis}

Methimazole-induced hypothyroidism promoted histomorphometrical changes in the proportion of germ cell cysts compared to the control (Fig. 2(A)-(D)). There was a significant increase in the proportion of the area occupied by type $A$ undifferentiated spermatogonia $\left(A_{\text {und* }}\right)$, type A differentiated $\left(\mathrm{A}_{\text {diff }}\right)$ and spermatogenic cysts containing type $\mathrm{B}$ spermatogonia $(\mathrm{SpgB})$ in the methimazole group as compared to control (Fig. 2 (D)). The number of meiotic cells (Spc) and postmeiotic haploid cell population (Spt) did not change between control and methimazole-treated group (Fig. 2 (D)). However, the number of spermatozoa reduced drastically when compared to control as clearly evidenced in the photomicrographs and analysis of spermatozoa number by field (Fig. 2(A), (B) and (E)). Co-treatment with $\mathrm{T} 4$ rescued the proportion of $\mathrm{A}_{\text {und* }}, \mathrm{A}_{\text {diff }}$ and SpgB types returned to its basal values, while the proportion area occupied by Spc and Spt significantly increased (Fig. 2 (D)). Interestingly, the production of spermatozoa was recovered in the co-treatment with T4 (as viewed in the fields of Fig. 2(A), (C) and (E)).

\subsection{Methimazole and co-treatment with T4: testicular transcript levels}

Transcript levels of several genes involved in reproduction were measured by qPCR in the testis from methimazole-induced hypothyroidism and rescued groups (methimazole + T4) (Fig. 3). In this study we measured transcript levels of two thyroid hormone receptor subtypes $(t h r \alpha, t h r \beta)$. The thro transcript level was higher in the methimazole treated group than control, but the difference was not statistically significant (Fig. 3(A)). The thro transcript level was further increased significantly in the methimazole + T4 treated group (Fig. 3(A)). Similarly, the thr $\beta$ was increased in the methimazole and methimazole + T4 treated groups, compared to the control (Fig. 3(B)).

We also measured mRNA levels of $f s h r$ which was not affected in the methimazole treated group, but significantly increased in the methimazole $+\mathrm{T} 4$ treated fish, compared to the control (Fig. 3(C)).

In the present study we measured transcript levels for cyp17al and insulin-like peptide 3 (insl3) genes. Treatment with methimazole significantly reduced the cyp $17 a 1$ and insl3 transcript levels compared to control (Fig. 3(D) and (E)). Co-treatment with T4 did not influence the methimazole induced response on the expression of these transcripts (Fig. 3(D) and (E)). We also observed significant reduction in the testicular connexin (cx43) mRNA levels in the methimazole treated group, compared to control (Fig. 3(F)). Co-treatment with T4 in this case increased the $c x 43$ mRNA to a level not significantly different from the control (Fig. 3(F)).

Among others, igf3, amh, and $g s d f$ genes are known to be expressed in the Sertoli cells. Treatment with methimazole or methimazole $+\mathrm{T} 4$ were without significant effects on igf 3 and amh transcript levels (Fig. 3(G) and (H)). The gsdf mRNA level, however, was higher in the methimazole and methimazole + T4 treated groups (Fig. 3(I)).

With regard to germ cell marker genes, such as marker for type A undifferentiated spermatogonia, nanos $2 \mathrm{mRNA}$ level was significantly higher in the methimazole treated group compared to control (Fig. 3(J)). Co-treatment with T4, significantly reduced the methimazoleinduced response to a level higher than the basal control (Fig.3(J)). The dazl (deleted-in azoospermia-like) transcript level expressed by $\mathrm{A}_{\text {diff }}$ and $\mathrm{SpgB}$, increased in the methimazole treated 
bioRxiv preprint doi: https://doi.org/10.1101/2022.01.30.478377; this version posted January $30,2022$. The copyright holder for this preprint (which was not certified by peer review) is the author/funder, who has granted bioRxiv a license to display the preprint in perpetuity. It is made available under aCC-BY-NC-ND 4.0 International license.

\section{Thyroid hormones deficiency impairs male germ cell development: a cross talk between hypothalamic-pituitary-thyroid, and - gonadal axes in zebrafish}

group compared to the control (Fig. 3(K)). Co-treatment with T4 did not influence the methimazoleinduced response (Fig. 3(K)). In our study, synaptonemal complex protein 3 ( $s y c p 3 l$ ) which is a marker for spermatocytes was not significantly affected by methimazole or methimazole $+\mathrm{T} 4$ treatments (Fig. 3(L)). However, the transcript level of the outer dense fiber protein 3 (odf $3 a$ ) which is a marker for spermatids was increased following treatment with methimazole (Fig. 3(M)). Cotreatment with T4 reduced the methimazole-induced response to a level not significantly different from the basal control (Fig. 3(M)).

\subsection{Measurement of 11-KT levels}

In the present study, we measured the 11-KT concentration to partially assess the effect of methimazole-induced hypothyroidism on steroidogenesis, in vivo and in vitro (Fig. 4(A)). Four treatment groups were studied in this experiment, including control, control $+\mathrm{T} 4$, methimazole and co-treatment (methimazole + T4) groups (Fig. 4(A)). Animal exposure with T4 (control+T4) significantly reduced the plasma 11-KT level as compared to control levels (Fig. 4(B)). Also, treatment with methimazole significantly reduced the plasma 11-KT concentration to almost undetectable level compared to the control level of over $40 \mathrm{ng} / \mathrm{mL}$ (Fig. 4(B)). However, cotreatment with T4 significantly increased and nullified the methimazole-induced response to a level not significantly different from the control (Fig. 4(B)).

We also measured the androgen (11-KT) release capacity of zebrafish testicular tissue using the ex vivo culture system (Fig. 4(A)). In this experiment, we compared testis taken from control and those exposed to T4 $(100 \mu \mathrm{g} / \mathrm{L})$, methimazole $(1 \mathrm{mM})$ and methimazole co-treated with $\mathrm{T} 4$. We tested the 11-KT release response into culture media following in vitro treatment for $18 \mathrm{~h}$ to recombinant zebrafish Fsh (100 ng/ml) (Fig. 4(A)). In the basal medium condition, the treatments (T4, methimazole and methimazole + T4) did not change the basal androgen (11-KT) release capacity of zebrafish testicular tissue (Fig. 4(C)). However, as expected, treatment with Fsh significantly increased the 11-KT level in the control group (Fig. 4(C)). Also, treatment with T4 was responsive to Fsh but to a level not significantly different from the control (Fig. 4(C)). In comparison, the isolated testis from methimazole-treated zebrafish was completely unresponsive to Fsh (Fig. 4(C)). However, co-treatment with T4 restored the Fsh-induced response by increasing the 11-KT concentration to the level observed following treatment of the control group with Fsh alone (Fig. 4(C)).

\subsection{Transcript levels of selected genes in the brain and pituitary}

In this experiment, we measured brain transcript levels of a number of neurohypothalamic peptides, including gnrh 2 and gnrh3, gnih, and $c r f$, as well as pituitary gonadotropin hormone subunits, $f s h b, l h b$, and $t s h b$ in the methimazole-induced hypothyroidism in fish (Fig. 5(A) and (C)). As shown in Fig. 5(C), we observed a significant increase in the gnih transcript level compared to the control shown as the dotted line. Transcript levels of the other neuropeptides measured including gnrh2, gnrh3 and crf remained unchanged. In the same group of methimazole-treated fish, the results the pituitary glycoprotein hormone subunits, demonstrate significant increase in $f s h b$ mRNA and a massive increase in $t s h b$ transcript levels in the methimazole-induced hypothyroid fish (Fig. 5(C)). No change was observed in the lhb transcript level (Fig. 5(C)). 


\section{Thyroid hormones deficiency impairs male germ cell development: a cross talk between hypothalamic-pituitary-thyroid, and - gonadal axes in zebrafish}

We also measured the same transcript levels following 12 hours acute treatment with $250 \mathrm{ng}$ of T3/fish in vivo (Fig. (B) and (D)). In this experiment T3 injection did not significantly alter gnih, gnrh2 and crf, but significantly increased the gnrh 3 transcript level (Fig. 5(D)). In the same group of fish, acute treatment with $250 \mathrm{ng}$ of T3/fish significantly reduced the pituitary lhb but was without effect on the $f s h b$ and $t s h b$ transcript levels (Fig. 5(D)).

\section{6 in vitro: effects of $\mathrm{T} 3$ on zebrafish spermatogenesis}

In this study, we also investigated the direct action of $\mathrm{T} 3$ at $100 \mathrm{nM} / \mathrm{mL}$ on ex vivo culture of zebrafish testis for 7 days (Fig. 6(A)) and results provide information on the proportion of germ cells in the cultured testis. Histomorphometrical evaluation of zebrafish testis revealed that treatment with T3 significantly stimulated the type A undifferentiated spermatogonia $\left(\mathrm{A}_{\text {und }}\right)$ abundance with no effect on type A differentiated spermatogonia cells as compared to basal medium incubation (Fig. 6(B)). In the same tissue, we observed a reduction in type B spermatogonia (SpgB) abundance (Fig. 6(B)). As for meiotic and post-meiotic cells, treatment with T3 reduced the proportion of area occupied by Spc and Spt when compared to basal condition (Fig. 6(B)). Interestingly, the number of spermatozoa was stimulated in zebrafish testis treated with T3 as clearly shown by the analysis of spermatozoa number by field (Fig. 6(C)). In addition to these data, we evaluated the effects of thyroid hormones on gene expression (Fig. 6 (D)-(G)) (see Supplementary Figure). Different concentrations of T3 and T4 (10, 100 and $1000 \mathrm{nM})$ were tested in zebrafish testis. T4 did not

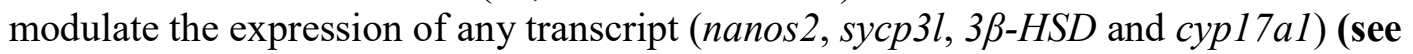

Supplementary Figure). On the other hand, expression analysis showed that T3 (100 and 1000 $\mathrm{nM} / \mathrm{mL}$ ) increased nanos 2 (Fig. 6 (D)). Interestingly, $\mathrm{T} 3$ also stimulates the sycp $3 l$, the meiotic marker expression (100 nM/mL) (Fig. 6 (E)). Levels of $3 \beta-H S D$ and cyp17al were also measured and did not change within any levels of T3 (Fig. 6(F)-(G)).

\section{Discussion}

This study demonstrated the importance of thyroid hormones as a factor controlling zebrafish spermatogenesis, using methimazole-induced hypothyroidism in fish as a model organism. Several other studies have used antithyroid agents to investigate the effects of thyroid hormones on vertebrate reproduction, including fish (Swapna et al., 2006; Weng et al., 2007; Sharma and Patiño, 2013; Sharma et al., 2016; Tovo-Neto et al, 2018; Figueiredo et al., 2019; Rodrigues et al., 2021). In our study, the efficacy of hypothyroidism was considered based on histological conditions of thyroid follicles. Our results demonstrated that thyroid follicles clearly disrupted following a three-week exposure to $1 \mathrm{mM}$ methimazole. However, the normal thyroid follicles were recovered after cotreatment with T4. Also, testicular connexin (cx43) levels as it is the potential target for thyroid hormones (Poguet et al., 2003; Gilleron et al., 2006). Interestingly, Gilleron and collaborators (2006) demonstrated that propylthiouracil (PTU; another thyroid disruptor) decreases $c x 43$ levels in rats. In our study, the lower expression of $c x 43$ in the methimazole group indicates that methimazole treatment led to hypothyroidism in the male zebrafish.

The present study provides clear evidence that hypothyroidism disrupts germ cell development in the zebrafish testis. Plasma concentration of androgen (11-KT) levels was significantly lower in the hypothyroid group when compared to that in the euthyroid group. Moreover, the relative mRNA levels of selected testicular genes expressed by somatic and germ cells were altered in hypothyroidism, and in addition to decreased 11-KT plasma levels, hypothyroidism 


\section{Thyroid hormones deficiency impairs male germ cell development: a cross talk between hypothalamic-pituitary-thyroid, and - gonadal axes in zebrafish}

induced by methimazole also impaired genes expressed in the brain and pituitary gland. We used cotreatment with $\mathrm{T} 4$, which is the primary secretory product of the thyroid gland, to potentially reverse the effects of methimazole treatment. In addition to these in vivo experiments, we also examined the acute effects of thyroid hormones in zebrafish testicular explants in the presence or absence of rzfFsh in different treatments. Thus, this study provides a novel and practical approach to better understand the nature of thyroid hormone actions on the HPG axis in male zebrafish.

Histomorphometric evaluation of zebrafish spermatogenesis demonstrated that methimazoleinduced hypothyroidism remarkably increased the proportion area occupied by type $\mathrm{A}_{\text {und*(the most }}$ undifferentiated spermatogonia), type $\mathrm{A}_{\text {diff }}$ and type $\mathrm{B}$ spermatogonia, while the number of spermatozoa was decreased. Furthermore, our results demonstrate that the proportion of Spc and Spt were not affected in hypothyroid testis compared with the control animals. It has been wellestablished that spermatogenesis development is supported and regulated by gonadotropic hormones, FSH and LH which mainly target actions on somatic testicular cells such as Sertoli and Leydig cells (Planas et al., 1993; Campbell et al., 2003; Huhtaniemi and Themmen, 2005; García-López et al., 2010; Schulz et al., 2010; Flood et al., 2013). Likewise, thyroid hormones have also been shown to play an essential role in testicular physiology (Chiao et al., 2002; Cooke et al., 2004; Holsberger and Cooke, 2005; Wagner et al., 2008; 2009; Morais et al., 2013; Tovo-Neto et al., 2018). In rats, previous studies have reported that hypothyroidism decreases plasma levels of gonadotropins and reduces the number and size of gonadotrophs (Bruni et al., 1975; Ruiz et al., 1988), suggesting that the absence of thyroid hormones is associated with gonadal dysfunctions (Amin and El-Sheikh, 1977; Hernandez, 2018). Further, the level of relevant androgen (11-KT) that stimulates spermatogenesis decreased significantly in the plasma of zebrafish following treatment with methimazole. These results, in part, could explain the observed increase in different populations of spermatogonia $\left(\mathrm{A}_{\text {und }}\right.$, $\mathrm{A}_{\mathrm{diff}}$ and $\mathrm{B}$ ) and decrease in spermatozoa number, demonstrating the impact of thyroid hormone depletion on germ cell development and testicular function. Similar findings have been reported for male Japanese quail, wherein treatment with methimazole decreased body and testes weight as well as plasma levels of LH and testosterone (Weng et al., 2007). In this same study, the data showed decreased spermatogenesis in seminiferous tubules of the treatment group (Weng et al., 2007). Altogether, these results demonstrate that gonadal function is associated with normal thyroid action. Fluctuations in thyroid hormone levels can directly modulate gonadotropin actions and affect Sertoli and Leydig cell proliferation (Castañeda-Cortés et al., 2014), resulting in the impairment of spermatogenesis, which may be caused by low FSH level and delay of Sertoli cell maturation (Hernandez, 2018).

We also examined the effects of methimazole co-treated with T4. Our results demonstrate that co-treatment with T4 partially restored zebrafish spermatogenesis and spermatozoa production in the methimazole-induced hypothyroid fish. Interestingly, the administration of T4 to the hypothyroid group increased the proportion of meiotic (Spc) and post-meiotic (Spt) cells compared with the control and methimazole groups. These results support the hypothesis that thyroid hormones are involved, directly or indirectly, with meiosis entry in the zebrafish testis.

The observed transcript analysis in zebrafish testis is to some extent in agreement with histomorphometric results. With respect to the germ cell markers genes of zebrafish spermatogenesis, the results indicated that mRNA levels of nanos2 (marker of type A undifferentiated spermatogonia) (Aoki et al., 2009) and dazl (marker of differentiation) (Chen et al., 2013) were higher in the methimazole group, in agreement with the histomorphometry showing an accumulation of premeiotic cells $\left(\mathrm{A}_{\text {und* }}, \mathrm{A}_{\mathrm{diff}}\right.$ and $\left.\mathrm{B}\right)$. The observed upregulation of these transcripts in the methimazole treated group suggest that euthyroid condition may be important for normal spermatogonial cell development in zebrafish. However, the level of odf3a (marker of spermatids) (Yano et al., 2008) 
bioRxiv preprint doi: https://doi.org/10.1101/2022.01.30.478377; this version posted January $30,2022$. The copyright holder for this preprint (which was not certified by peer review) is the author/funder, who has granted bioRxiv a license to display the preprint in perpetuity. It is made available under aCC-BY-NC-ND 4.0 International license.

\section{Thyroid hormones deficiency impairs male germ cell development: a cross talk between hypothalamic-pituitary-thyroid, and - gonadal axes in zebrafish}

was upregulated in the methimazole group, although the proportion of spermatids was not affected in the present study. The affected testicular functions did not always recover following co-treatment with T4 to counter hypothyroidism.

Other important components of the thyroid hormones axis are the thyroid receptors (TRs), which are crucial for testis development and function (Valadares et al., 2008; Dittrich et al., 2011; Lema et al., 2009; Wajner et al., 2009). According to Habibi et al., (2012), TRs are expressed by several different cell types, and thyroid hormones have pleiotropic effects, including effects on the gonads. In the latter study in goldfish, in vivo and in vitro, thyroid hormones were shown to exert both direct and indirect actions on gonadal steroid synthesis, and steroid receptor expression in a seasonally dependent manner (Allan and Habibi, 2012; Habibi et al., 2012). In zebrafish testis, thro was shown to be expressed in the Sertoli and Leydig cells, whereas thr $\beta$ expression was only observed in the Leydig cell (Morais et al., 2013). In the present study, methimazole-induced hypothyroidism stimulated $t h r \beta$ transcript level, but increase in thro was only significant in presence of T4 compared to control. Other investigators also reported that T3 treatment only elevated thr $\beta$ in the ovary and testis of Pimephales promelas (Lema et al., 2009). Similarly, $f s h r$ mRNA levels were also upregulated in hypothyroid co-treated with T4. These results suggest that chronic hyperthyroidism may alter thyroid hormone sensitivity and possibly alter other parameters not clear at the present time. Similarly, in rats, higher FSH-R mRNA levels were detected in hypothyroidism. It was suggested that the upregulated FSH-R mRNA level may have resulted from the elevated proportion of Sertoli cells in rats (Rao et al., 2003). Likewise in zebrafish, the increase of $f s h r$ transcripts following co-treatment with T4 could be due to Sertoli cell proliferation. Morais et al., (2013) showed that T3 stimulates in vitro Sertoli cell proliferation in zebrafish testes. Moreover, in zebrafish testis, Sertoli cells express both $t h r \alpha$ and $f s h r$, and treatment with T3 potentiates Fsh action in the zebrafish testis in vitro (Morais et al., 2013). This is also consistent with the observation that $f s h r$ transcript level was stimulated by methimazole-induced hypothyroid fish co-treated with T4. These results support the view that thyroid hormones and gonadotropins stimulate spermatogenesis by stimulating gonadal androgen production, which in turn mediate the start of spermatogenesis.

Interestingly, mRNA expression of other key gonadal growth factors as igf 3 (Wang et al., 2008) and $a m h$ (Miura et al., 2002) did not change in the methimazole or methimazole co-treated with T4 groups. However, gsdf (Gautier et al., 2011) was upregulated in both groups. $g s d f$ is expressed by Sertoli cells and exerts a crucial role in the control of germ cell proliferation and differentiation in spermatogenesis (Gautier et al., 2011; Yan et al., 2017).

Decreased thyroid hormones levels by methimazole in male zebrafish are associated with decreased 11-KT plasma levels. Previous studies have shown that PTU treatment also decreases serum testosterone concentrations in rats (Chiao et al., 2000). In another study, exposure of Clarias gariepinus to thiourea, reduced androgen levels leading to testicular regression (Swapna et al., 2006; Swapna and Senthikumaran, 2007). This is consistent with the present study demonstrating lower 11KT plasma levels in the methimazole group, in addition to lower levels of steroidogenic enzyme (cyp17a1) and androgen-sensitive gene (insl3) mRNA levels. These transcript levels remained the same even after co-treatment with T4. However, treatment of methimazole-induced hypothyroid fish effectively rescued 11-KT levels in the plasma which was correlated with the revival of spermatozoa number in zebrafish testis. Thus, impairing thyroid action within the physiological limit of restoration is a valid approach to explain the role of thyroid hormones in male zebrafish reproduction. Interestingly, Houbrechts and collaborators (2019) demonstrated the Dio2-knockout (KO) zebrafish (dio2 $2^{-}$) strongly decreased androgen (11-KT and testosterone) levels in the testis, and steroidogenesis and steroid signaling were similarly affected when compared with control animals. This indicates that absence of thyroid hormones by goitrogen treatment or DIO2 KO, which 
bioRxiv preprint doi: https://doi.org/10.1101/2022.01.30.478377; this version posted January $30,2022$. The copyright holder for this preprint (which was not certified by peer review) is the author/funder, who has granted bioRxiv a license to display the preprint in perpetuity. It is made available under aCC-BY-NC-ND 4.0 International license.

\section{Thyroid hormones deficiency impairs male germ cell development: a cross talk between hypothalamic-pituitary-thyroid, and - gonadal axes in zebrafish}

suppresses thyroid hormone production, may act directly on the testis to repress steroidogenesis. These data also indicate that normal thyroid hormone levels are crucial to normal reproduction in zebrafish.

The result in this study helps to elucidate the mechanisms underlying the observed reduction in androgen level in male zebrafish following treatment with methimazole. While transcript levels of gnrh2 and gnrh3 did not change, gnih mRNA levels were significantly elevated in the brain of animals after methimazole exposure. In fish, GnIH orthologs have double mechanism, including stimulatory and inhibitory actions on gonadotropin secretion and growth hormone production, depending on the species studied, mode of treatment, and season (Amano et al., 2006; Zhang et al., 2010; Moussavi et al., 2012; 2013; 2014; Branco et al., 2018; Fallah et al., 2019; Ma et al., 2020a, b). In addition, Tsutsui and collaborators (2017) showed that hypothyroidism induced by PTU increases $\mathrm{GnIH}$ expression and reduces gonadotropins and plasma steroid levels in female mice. The present results support the hypothesis that decrease in plasma androgen level in methimazole group is associated with the inhibition of the hypothalamic-pituitary-gonadal axis mediated, in part, by increased GnIH. As shown previously in goldfish, GnIH mediated inhibition of reproduction does not always correlate closely by inhibition of gonadotropin transcript levels due to uncoupling of release and synthesis. In this context, it was demonstrated that $\mathrm{GnIH}$ can increase gonadotropin subunit mRNA levels while reducing secretion of the hormones (Moussavi et al., 2012; 2013; 2014; Ma et al., 2020a, b). Thus, the inhibition may be at the protein level, since $f s h b$ transcript level was increased in the pituitary of the methimazole-treated group. Similarly, Yoshiura and collaborators (1999) found in goldfish that thiourea treatment per two weeks increased Fsh mRNA levels. A contributing factor could be due to feedback exerted by lower plasma 11-KT levels seen in these animals (Rojdmark et al., 1988; Trudeau et al., 1993; Habibi and Huggard-Nelson, 1998; HuggardNelson et al., 2002). There is increasing evidence that the effects of thyroid hormones as well as brain-pituitary-gonadal hormones are diverse, and change with season, mode of action, time-course, and concentration (Nelson and Habibi 2006, 2008, 2009; Nelson et al., 2011; Habibi et al., 2012; Moussavi et al., 2012, 2013, 2014; Nelson and Habibi 2016; Ma et al., 2020a, b). This is reflected in the present study as acute treatment for 12 hours with $\mathrm{T} 3$ injection resulting in a different effect than chronic treatments with T4 and methimazole on the hypothalamic-pituitary-gonadal axis. Injection with T3 increased gnrh 3 mRNA levels and either decreased $(l h b)$ or had no effects $(f s h b, t s h)$ on the pituitary glycoprotein hormone subunit transcript levels. This is consistent with previous study in goldfish demonstrating reduction in gonadotropins and synthesis of gonadal steroids following 12 hour injection with T3 (Nelson et al., 2010).

In addition to these data, we evaluated the effects of thyroid hormones on zebrafish spermatogenesis. Histomorphometrical analysis showed an increase of type A undifferentiated spermatogonia $\left(A_{u n d}\right)$ proportion in $\mathrm{T} 3$ in vitro exposure $(100 \mathrm{nM} / \mathrm{mL})$, which may reflect the upregulation of nanos 2 (marker of type A undifferentiated spermatogonia) $(100$ and $1000 \mathrm{nM} / \mathrm{mL}$ of T3). The number of spermatozoa also increased. This data corroborates the histomorphometry of the zebrafish testes from in vivo exposures using methimazole and methimazole co-treated with T4, indicating, therefore, a direct action of thyroid hormones in the zebrafish spermatogenesis. Previously, Morais et al. (2013) reported that the mitotic indices of $A_{\text {und }}$ and Sertoli cells were stimulated after T3 treatment. Also, Safian et al. (2016) demonstrated that T3 enhanced the formation of new cysts of $A_{\text {und }}$, accumulation of differentiated spermatogonia $\left(\mathrm{A}_{\text {diff }}\right)$ and reduction of spermatogonia B. Morais et al. (2013) using lower dose $(50 \mathrm{ng} / \mathrm{mL})$ reported an increase of type A undifferentiated spermatogonia, which was corroborated by higher BrdU mitotic index of this cell type in T3-treated tissue. In this study, we also examined the effects of T3 and T4 on gene expression. Different concentrations of T3 and T4 (10, 100 and $1000 \mathrm{nM})$ were tested in zebrafish 


\section{Thyroid hormones deficiency impairs male germ cell development: a cross talk between hypothalamic-pituitary-thyroid, and - gonadal axes in zebrafish}

testis. Interestingly, T3 also stimulated the sycp $3 l$, the meiotic marker expression $(100 \mathrm{nM} / \mathrm{mL})$. Levels of $3 \beta-H S D$ and cyp $17 a 1$ were also measured and did not change within any level of T3. Another interesting result is that T4 does not exert any change. Thyroid hormones act via T3 in zebrafish testis. Altogether this data indicates that thyroid hormones (T3) stimulate zebrafish spermatogenesis by proliferation, differentiation, and meiosis. These results supply important data about the effects of thyroid hormones on brain-pituitary-testis and support interaction between reproductive and thyroid axes via neurohypothalamic peptides and gonadotropins (e.g. Fsh), which needs $\mathrm{T} 3$ to promote its functions in zebrafish testis.

\section{Conclusion}

The present study clearly demonstrated that hypothyroidism induced by methimazole significantly impair the progression of zebrafish spermatogenesis by inducing the accumulation of pre-meiotic cells, delaying differentiation and meiosis, and reducing the number of spermatozoa as well as impairing the hypothalamic-pituitary axis. We also provide evidence that testicular function is dependent on thyroid hormones. Taken together, these results provide support for that hypothesis that thyroid hormones are essential for spermatogenesis and maintaining normal function of the hypothalamic-pituitary-gonadal axis in adult zebrafish.

\section{Conflict of Interest}

The authors declare that the research was conducted in the absence of any commercial or financial relationships that could be construed as a potential conflict of interest.

\section{Author Contributions}

R.H.N., M.S.R., A.T.N., and H.R.H. designed the study; M.S.R., A.T.N., I.F.R., L.B.D., and H.P.F performed the experiments; All authors analyzed the data; R.H.N., M.S.R., A.T.N., and H.R.H. wrote the paper. All authors edited the article.

\section{Funding}

This work was supported by the São Paulo Research Foundation (FAPESP 2017/15793-7 and 2018/15319-6) to M.S.R., (FAPESP 2014/07620-7 and 2020/03569-8) to R.H.N. and Natural Sciences and Engineering Research Council of Canada to H.R.H. (NSERC Discovery Grant; project no. 1021837).

\section{Table legend}

Table 1. Primers used for gene expression studies (qPCR). (FW= Forward; RV = Reverse).

\section{Figures legends}

Figure 1: (A) Experimental design representation of treatments: control (non-treated fish), methimazole $(1 \mathrm{mM})$ and methimazole $(1 \mathrm{mM})+\mathrm{T} 4(100 \mu \mathrm{g} / \mathrm{L})$ groups. Zebrafish adult males were exposed to reconstituted water containing $1 \mathrm{mM}$ methimazole (goitrogen) for three-weeks or $1 \mathrm{mM}$ methimazole following T4 $(100 \mu \mathrm{g} / \mathrm{L})$ added in the water from the second week until the end of experiment. The control group received the same volume of vehicle solution. After 21 days heads were collected for histological analysis (B-D). Control animals (B) have thyroid follicles with 


\section{Thyroid hormones deficiency impairs male germ cell development: a cross talk between hypothalamic-pituitary-thyroid, and - gonadal axes in zebrafish}

604

605

606

607

608

609

610

611

612

613

614

615

616

617

618

619

620

621

622

623

624

625

626

627

628

629

630

631

632

633

634

635

636

637

638

639

640

641

642

643

644

645

646

647

648

649

squamous/cuboidal epithelial cells and are completely filled with colloid. Fish treated with methimazole (C) showed follicles with columnar epithelium, follicle cell hypertrophy and colloid depletion, while fish co-treated with T4 (D) showed follicles similar to the control animals. Staining: Toluidine blue with sodium borate. Scale bar $=20 \mu \mathrm{m}$.

Figure 2: Histomorphometrical evaluation of zebrafish testes after in vivo exposure to methimazole and co-treatment with T4 for 21 days. Control group (non-treated fish) (A). Methimazole-treated group (B). Methimazole co-treated with T4 (C). Asterisks in (A), (B) and (C) indicate the testicular lumen with spermatozoa that appeared reduced in the methimazole group. (D) Proportion of section area occupied by spermatogenic cysts containing types $A$ undifferentiated spermatogonia $\left(A_{\text {und*, }}\right.$ $\left.\mathrm{A}_{\text {und }}\right)$, A differentiated spermatogonia $\left(\mathrm{A}_{\text {diff }}\right)$, B spermatogonia $(\mathrm{SpgB})$, spermatocytes $(\mathrm{Spc})$, and spermatids (Spt). Bars (mean $\pm \mathrm{SEM} ; \mathrm{n}=8$ ) are expressed as fold-change relative to the untreated group (control) (dotted line set at 1). (E) Spermatozoa number per field generated by using IMAGEJ Software from control and treatments. ANOVA followed by Dunnett's multiple comparison tests. Different letters denote significant differences $(p<0.05)$ between different treatment conditions with the control. Asterisks denote statistical significance differences between control, methimazole and methimazole $+\mathrm{T} 4$ groups; $* p<0.05 ; * * p<0.01$ (Student unpaired $t$-test; $\mathrm{n}=8$ ). Staining:

Toluidine blue. Scale bar $=50 \mu \mathrm{m}$.

Figure 3: Relative mRNA levels of several genes expressed in zebrafish testis after in vivo exposure to methimazole and methimazole co-treated with T4 for 21 days. The selected genes thr $\alpha$ and $t h r \beta$ (thyroid hormones receptor) (A-B); $f s h r$ (follicle-stimulating hormone receptor) (C); genes expressed by somatic cells (Leydig and Sertoli cells) (D-I); cyp17al (17 -hydroxylase/17,20 lyase) (D); insl3 (insulin-like peptide 3) (E); cx43 (testicular connexin) (F); igf3 (insulin-like growth factor 3) (G); amh (anti-Müllerian hormone) (H); gsdf (gonadal somatic cell derived factor) (I); and germ cell markers (J-M); nanos 2 (J); dazl (deleted-in azoospermia-like) (K); sycp3l (synaptonemal complex protein 3) (L); odf3a (outer dense fiber of sperm tails 3B) (M) were evaluated. Ct values were normalized with $\beta$-actin and expressed as relative values of control levels of expression. Bars represent the mean \pm SEM fold change $(n=8)$ relative to the control, which is set at 1 . Student unpaired $t$-test. Different letters denote significant differences $(p<0.05)$ between different treatment conditions with the control.

Figure 4: (A) Experimental design. 11-Ketotestosterone (11-KT) plasma levels (ng/mL plasma) was measured in zebrafish males exposed to different treatments: Control (non-treated fish), T4 $(100 \mu \mathrm{g} / \mathrm{L})$, methimazole $(1 \mathrm{mM})$ and methimazole $(1 \mathrm{mM})+\mathrm{T} 4(100 \mu \mathrm{g} / \mathrm{L})$. Amounts of $11-\mathrm{KT}$ (ng/mg of testis weight) released by zebrafish testes were measured in the incubation media after short-term exposure $(18 \mathrm{~h})$ in the presence or absence of Fsh $(100 \mathrm{ng} / \mathrm{mL})$ from control, T4, methimazole and methimazole + T4 groups. (B) Effect of T4, methimazole and combination of methimazole and T4 on 11-KT plasma levels. (C) Androgen (11-KT) release from zebrafish testicular explants previously treated with T4, methimazole or methimazole co-treated with T4. Bars represent the mean \pm SEM $(n=8)$. ANOVA followed by Tukey's test. Different letters denote significant difference $(p<0.05)$ between different treatments compared to the respective control group.

Figure 5: (A) Experiment 1: zebrafish males were exposed to methimazole-induced hypothyroidism for 21 days. (B) Experiment 2: zebrafish males were injected with 0 or $250 \mathrm{ng}$ of T3/fish and tissue were collected $12 \mathrm{~h}$ post-injection. Relative mRNA levels of selected genes, including gnrh 2 and gnrh3 (gonadotropin-releasing hormones), gnih (gonadotropin-inhibitory hormone), and crf 


\section{Thyroid hormones deficiency impairs male germ cell development: a cross talk between hypothalamic-pituitary-thyroid, and - gonadal axes in zebrafish}

(corticotropin-releasing hormone), expressed in the brain $(\mathrm{n}=8)$, and $\operatorname{lh} \beta$ (luteinizing hormone), $f_{s} h \beta$ (follicle-stimulating hormone), and $t \operatorname{sh} \beta$ (thyroid-stimulating hormone) expressed in the pituitary ( $\mathrm{n}=$ 4 pools of 4 pituitaries for each pool) from the methimazole group (C) and $12 \mathrm{~h}$ post-injection with 0 and $250 \mathrm{ng}$ of T3/fish (D). Ct values were normalized with $\beta$-actin and expressed as relative values of control $(0 \mathrm{ng} / \mathrm{mL})$ levels of expression. Bars represent mean \pm SEM fold-change relative to the control, which is set at 1 . Student unpaired $t$-test, ${ }^{*} p<0.05,{ }^{* *} p<0.01$ and $* * * p<0.001$.

Figure 6: (A) Experimental design of histomorphometrical analysis of zebrafish testicular explants incubated for 7 days (long-term exposure) with T3 $(100 \mathrm{nM} / \mathrm{mL})$ compared to the control (basal) and gene expression of relative mRNA levels of several selected genes in zebrafish testis incubated for 7 days to different concentrations of T3 $(0,10,100$ e $1000 \mathrm{nM} / \mathrm{mL})$. (B) Histomorphometrical evaluation of testicular explants containing types $A$ undifferentiated spermatogonia $\left(A_{\text {und }} * A_{\text {und }}\right)$, type A differentiated spermatogonia $\left(\mathrm{A}_{\text {diff }}\right)$, type $\mathrm{B}$ spermatogonia $(\mathrm{SpgB})$, spermatocytes $(\mathrm{Spc})$, and spermatids (Spt). Bars (mean $\pm \mathrm{SEM} ; \mathrm{n}=8$ ) are expressed as fold-change relative to the untreated group (control) (dotted line set at 1). (C) Spermatozoa number per field generated by using IMAGEJ Software from zebrafish explants incubated for 7 days with basal (L-15) and T3 (100 nM/mL). Bars (mean \pm SEM; $\mathrm{n}=8$ ). Student paired $t$-test, ${ }^{*} p<0.05$ and ${ }^{* * *} p<0.001$ denote significant differences between control and treated fish. The selected genes nanos 2 (D), sycp $3 l$ (synaptonemal complex protein 3) (E), 3 $\beta$-HSD (3-beta ( $\beta$ )-hydroxysteroid dehydrogenase) (F), and cyp 17al (17 $\alpha$ hydroxylase/17,20 lyase/17,20 desmolase) (G) were evaluated. Ct values were normalized with $\beta$ actin and expressed as relative values of basal $(0 \mathrm{ng} / \mathrm{mL})$ levels of expression. Bars represent the mean \pm SEM fold change $(\mathrm{n}=8)$, relative to the control (basal, $0 \mathrm{ng} / \mathrm{mL})$, which is set at 1 . Paired $t-$ test, ${ }^{*} p<0.05, * * p<0.01$.

Supplementary Figure: (A) Relative mRNA levels of several genes expressed in zebrafish testis after incubated for 7 days to different concentrations of T4 $(0,10,100$ e $1000 \mathrm{nM} / \mathrm{mL})$. The selected genes nanos2 (B), sycp3l (synaptonemal complex protein 3) (C), 3 $\beta$-HSD (3-beta ( $\beta$ )-hydroxysteroid dehydrogenase) (D), and cyp17al (17 $\alpha$-hydroxylase/17,20 lyase/17,20 desmolase) (E) were evaluated. Ct values were normalized with $\beta$-actin and expressed as relative values of basal $(0$ $\mathrm{ng} / \mathrm{mL})$ levels of expression. Bars represent the mean \pm SEM fold change $(\mathrm{n}=8)$, relative to the control (basal, $0 \mathrm{ng} / \mathrm{mL}$ ), which is set at 1 . Paired $t$-test.

\section{References}

Allan, E.R.O., Habibi, H.R. (2012). Direct effects of triiodothyronine on production of anterior pituitary hormones and gonadal steroids in goldfish. Mol Reprod Dev. 79: 592-602. doi:10.1002/mrd.22066.

Amano, M., Moriyama, S., Iigo, M., Kitamura, S., Amiya, N., Yamamori, K., Ukena, K., Tsutsui, K. (2006). Novel fish hypothalamic neuropeptides stimulate the release of gonadotrophins and growth hormone from the pituitary of sockeye salmon. $J$ Endocrinol.188:417-423. doi: 10.1677/joe.1.06494.

Amin, S.O., El-Sheikh, A.S. (1977). Pituitary-testicular function changes in hypo- and hyperthyroid male rats. Acta Anatomica. 98:121-129. doi:10.1159/000144788. 
bioRxiv preprint doi: https://doi.org/10.1101/2022.01.30.478377; this version posted January 30,2022 . The copyright holder for this preprint (which was not certified by peer review) is the author/funder, who has granted bioRxiv a license to display the preprint in perpetuity. It is made available under aCC-BY-NC-ND 4.0 International license.

\section{Thyroid hormones deficiency impairs male germ cell development: a cross talk between hypothalamic-pituitary-thyroid, and - gonadal axes in zebrafish}

Ariyaratne, H.B.S., Mason, J.I., Mendis-Handagama, S.M. (2000). Effects of thyroid and luteinizing hormones on the onset of precursor cell differentiation into Leydig progenitor cells in the prepubertal rat testis. Biol Reprod. 63:898-904. doi:10.1095/biolreprod63.3.898.

Aoki, Y., Nakamura, S., Ishikawa, Y., Tanaka, M. (2009). Expression and syntenic analyses of four nanos genes in medaka. Zool Sci. 26:112-118. doi:10.2108/zsj.26.112.

Blanton, M.L., Specker, J.L. The hypothalamic-pituitary-thyroid (HPT) axis in fish and its role in fish development and reproduction. (2007). Crit Rev Toxicol. 37:97-115. doi:10.1080/10408440601123529.

Branco, G. S., Melo, A. G., Ricci, J. M. B., Digmayer, M., De Jesus, L. W. O., Habibi, H. R., Nóbrega, R. H. (2018). Effects of GnRH and the dual regulatory actions of GnIH in the pituitary explants and brain slices of Astyanax altiparanae males. Gen Comp Endocrinol. 273:209-217. doi: 10.1016/j.ygcen.2018.08.006.

Bruni, J.F., Marshall, S., Dibbet, J.A., Meites, J. (1975). Effects of hyper- and hypothyroidism on serum LH and FSH levels in intact and gonadectomized male and female rats. Endocrinol. 97:558563. doi:10.1210/endo-97-3-558.

Campbell, B., Dickey, J.T., Swanson, P. (2003). Endocrine changes during onset of puberty in male spring Chinook salmon, Oncorhynchus tshawytscha. Biol Reprod. 69:2109-2117. doi: 10.1095/biolreprod.103.020560.

Carr, J.A., Patiño, R. (2011). The hypothalamus-pituitary-thyroid axis in teleosts and amphibians: endocrine disruption and its consequences to natural populations. Gen Comp Endocrinol. 170: 299312. doi:10.1016/j.ygcen.2010.06.001.

Castañeda-Cortés, D.C., Langlois, V.S., Fernandino, J.I. (2014). Crossover of the hypothalamic pituitary-adrenal/interrenal, -thyroid, and-gonadal axes in axes in testicular development. Front. Endocrinol. 139:1-11. doi: doi.org/10.3389/fendo.2014.00139.

Chen, S.X., Bogerd, J., Schoonen, N.E., Martijn, J., De Waal, P.P., Schulz, R.W. (2013). A progestin (17a,20ß-dihydroxy-4-pregnen-3-one) stimulates early stages of spermatogenesis in zebrafish. Gen Comp Endocrinol. 185:1-9. doi:10.1016/j.ygcen.2013.01.005.

Chiba, H., Amano, M., Yamada, H., Fujimoto, Y., Ojima, D., Okuzawa, K., Yamanome, T., Yamamori, K., Iwata, M. (2004). Involvement of gonadotropin releasing hormone in thyroxine release in three different forms of teleost fish: barfin flounder, masu salmon and goldfish. Fish Physiol Biochem. 30:267-273. doi:10.1007/s10695-005-8676-y.

Cyr, D.G., Eales, J.G. (1996). Interrelationships between thyroidal and reproductive endocrine systems in fish. Rev Fish Biol Fisheries. 6:165-200. doi:10.1007/BF00182342.

Cooke, P.S., Meisami, E. (1991). Early postnatal hypothyroidism causes increased adult size of testis and other reproductive organs but does not increase testosterone levels. Endocrinol. 129:237-243. doi:10.1210/endo-129-1-237. 


\section{Thyroid hormones deficiency impairs male germ cell development: a cross talk between hypothalamic-pituitary-thyroid, and - gonadal axes in zebrafish}

Cooke, P.S., Zhao, Y-D., Bunick, D. (1994). Triiodothyronine inhibits proliferation and stimulates differentiation of cultured neonatal Sertoli cells: possible mechanism for increased adult testis weight and sperm production induced by neonatal goitrogen treatment. Biol Reprod. 51:1000-1005. doi: 10.1095/biolreprod51.5.1000.

Cooke, P.S., Holsberger, D.R., Witorsch, R.J., Sylvester, P.W., Meredith, J.M., Treinen, K.A. Chapin, R.E. (2004). Thyroid hormone, glucocorticoids, and prolactin at the nexus of physiology, reproduction, and toxicology. Toxicol Appl Pharmacol. 14:309-35. doi: 10.1016/j.taap.2003.09.016. Chiao, Y.C., Lin, H., Wang, S.-W., Wang, P. S. (2000). Direct effects of propylthiouracil on testosterone secretion in rat testicular interstitial cells. Br J Pharmacol. 130:1477-1482. doi:10.1038/sj.bjp.0703444.

Chiao, Y.C., Cho, W.L., Wang, P.S. (2002). Inhibition of testosterone production by propylthiouracil in rat Leydig cells. Biol Reprod. 67:416-22. doi:10.1095/biolreprod67.2.416.

Dittrich, R., Beckmann, M.W., Oppelt, P.G., Hoffmann, I., Lotz, L., Kuwert, T. (2011). Thyroid hormone receptors and reproduction. J Reprod Immunol. 90:58-66. doi:10.1016/j.jri.2011.02.009.

Duarte-Guterman, P., Navarro-Martín, L., Trudeau, V.L. (2014). Mechanisms of crosstalk between endocrine system: Regulation of sex steroid hormone synthesis and action by thyroid hormones. Gen Comp Endocrinol. 203:69-85. doi:10.1016/j.ygcen.2014.03.015.

Fallah, H. P., Tovo-Neto, A., Yeung, E. C., Nóbrega, R. H., Habibi, H. R. (2019). Paracrine/autocrine control of spermatogenesis by gonadotropin-inhibitory hormone. Mol Cell Endocrinol. 492:110440. doi:10.1016/j.mce.2019.04.020.

Fallah, H.P., Rodrigues, M.S., Corchuelo, S., Nóbrega, R.H., Habibi, H.R. (2020). Role of GnRH isoforms in paracrine/autocrine control of zebrafish (Danio rerio) spermatogenesis.

Endocrinol. 161:1-16. doi:10.1210/endocr/bqaa004.

França, L.R., Hess, C.A., Cooke, P.S., Russel, L.D. (1995). Neonatal hypothyroidism causes delayed Sertoli cell maturation in rats treated with propylthiouracil: evidence that the Sertoli cell controls testis growth. The Anatomical Record. 242:57-69. doi:10.1002/ar.1092420108.

Flood, D.E.K., Fernandino, J.I., Langlois, V.S. (2013). Thyroid hormones in male reproductive development: Evidence for direct crosstalk between the androgen and thyroid hormone axes. Gen Comp Endocrinol. 192:2-14. doi:10.1016/j.ygcen.2013.02.038.

Figueiredo, A.F.A., Wnuk, N.T., Tavares, A.O., Miranda, J.R., Hess, R.A., França, L.R., Costa, G.M.J. (2019). Prepubertal PTU treatment in rat increases Sertoli cell number and sperm production. Reprod. 158:199-209. doi: 10.1530/REP-19-0127.

García-López, A., Jonge, H., Nóbrega, R.H., Waal, P.P., Van Dijk, W., Hemrika, W., Taranger, G.L., Bogerd, J., Schulz, R.W. (2010). Studies in zebrafish reveal unusual cellular expression patterns of gonadotropin receptor messenger ribonucleic acids in the testis and unexpected functional differentiation of the gonadotropins. Endocrinology. 151-2349-60. doi:10.1210/en.2009-1227.

Gautier, A., Sohm, F., Joly, J.-S., Le Gac, F., Lareyre, J.-J. (2011). The proximal promoter region of the zebrafish gsdf gene is sufficient to mimic the spatio-temporal expression pattern of the 
bioRxiv preprint doi: https://doi.org/10.1101/2022.01.30.478377; this version posted January 30,2022 . The copyright holder for this preprint (which was not certified by peer review) is the author/funder, who has granted bioRxiv a license to display the preprint in perpetuity. It is made available under aCC-BY-NC-ND 4.0 International license.

\section{Thyroid hormones deficiency impairs male germ cell development: a cross talk between hypothalamic-pituitary-thyroid, and - gonadal axes in zebrafish}

781

782

783

784

785

786

787

788

789

790

791

792

793

794

795

796

797

798

799

800

801

802

803

804

805

806

807

808

809

810

811

812

813

814

815

816

817

endogenous gene in sertoli and granulosa cells. Biology of Reproduction. 85:1240-1251. doi: 10.1095/biolreprod.111.091892.

Gilleron, J., Nebout, M., Scarabelli, L., Senega-Balas, F., Palmero, S., Segretain, D., Pointis, G. A. (2006). Potential novel mechanism involving connexin 43 gap junction for control of sertoli cell proliferation by thyroid hormones. Journal of Cellular Physiology. 209:153-161. doi: $10.1002 /$ jcp.20716.

Habibi, H.R., Huggard-Nelson, D. L. (1998). Testosterone regulation of gonadotropin production in goldfish. Comp Biochem Physiol C Pharmacol Toxicol Endocrinol. 119:339-44. doi: 10.1016/s07428413(98)00022-x.

Habibi, H.R., Nelson, E.R., Allan, E.R.O. (2012). New insights into thyroid hormone function and modulation of reproduction in goldfish. Gen Comp Endocrinol. 175:19-26. doi:

10.1016/j.ygcen.2011.11.003.

Hernandez, A. (2018). Thyroid hormone role and economy in the developing testis. Vitam Horm. 106:473-500. doi:10.1016/bs.vh.2017.06.005.

Hess, R.A, Cooke, P.S, Bunick, D., Kirby, J.D. (1993). Adult testicular enlargement induced by neonatal hypothyroidism is accompanied by increased Sertoli and germ cell numbers. Endocrinol. 132:2607-2613. doi:10.1210/endo.132.6.8504761.

Houbrechts, A.M., Houcke, J.V., Veerle, M.D. (2019). Disruption of deiodinase type 2 in zebrafish disturbs male and female reproduction. J Endocrinol. 241:111-123. doi:10.1530/JOE-18-0549.

Holsberger, D.R., Cooke, P.S. (2005). Understanding the role of thyroid hormone in Sertoli cell development: a mechanistic hypothesis. Cell Tissue Res. 322:133-40. doi: 10.1007/s00441-0051082-z.

Huggard-Nelson, D.L., Nathwani, P.S., Kermouni, A., Habibi, H.R. (2002). Molecular characterization of LH-beta and FSH-beta subunits and their regulation by estrogen in the goldfish pituitary. Mol Cell Endocrinol. 188:171-193. doi:10.1016/s0303-7207(01)00716-x.

Huhtaniemi, I.T., Themmen, A.P. (2005). Mutations in human gonadotropin and gonadotropin receptor genes. Endocrine. 26:207-217. doi: 10.1385/ENDO:26:3:207.

Jacobs, G.F.M., Michielsen, R.P., Kuhn, E.R. (1988). Thyroxine and triiodothyronine in plasma and thyroids of the neotenic and metamorphosed axolotl Ambystoma mexicanum: influence of TRH injections. Gen Comp Endocrinol. 70:145-151. doi:10.1016/0016-6480(88)90103-7.

Jansen, H.T., Kirby, J.D., Cooke, P.S., Arambepola, N., Iwamoto, G.A. (2007). Impact of neonatal hypothyroidism on reproduction in the male hamster, Mesocricetus auratus. Physiol Behav. 90:771781. doi:10.1016/j.physbeh.2006.12.017.

Kang, H., Kenealy, T. M., Cohen, R. E. (2020). The hypothalamic-pituitary-gonadal axis and thyroid hormone regulation interact to influence seasonal breeding in green anole lizards (Anolis carolinensis). Gen Comp Endocrinol. 292:113446. doi:10.1016/j.ygcen.2020.113446. 
bioRxiv preprint doi: https://doi.org/10.1101/2022.01.30.478377; this version posted January 30,2022 . The copyright holder for this preprint (which was not certified by peer review) is the author/funder, who has granted bioRxiv a license to display the preprint in perpetuity. It is made available under aCC-BY-NC-ND 4.0 International license.

\section{Thyroid hormones deficiency impairs male germ cell development: a cross talk between hypothalamic-pituitary-thyroid, and - gonadal axes in zebrafish}

Larsen, D.A., Swanson, P., Dickey, J.T., Rivier, J., Dickhoff, W.W. (1998). In vitro thyrotropinreleasing activity of corticotropin-releasing hormone-family peptides in coho salmon, Oncorhynchus kisutch. Gen Comp Endocrinol. 109:276-285. doi:10.1006/gcen.1997.7031.

Leal, M.C., De Waal, P.P., García-López, A., Chen, S.X., Bogerd, J., Schulz, R.W. (2009). Zebrafish primary testis tissue culture: An approach to study testis function ex vivo. Gen Comp Endocrinol.162:134-138. doi:10.1016/j.ygcen.2009.03.003.

Lema, S., Dickey, J., Schultz, I.R., Swanson, P. (2009). Thyroid hormone regulation of mRNAs encoding thyrotropin beta-subunit, glycoprotein alpha-subunit, and thyroid hormone receptors alpha and beta in brain, pituitary gland, liver, and gonads of an adult teleost, Pimephales promelas. $J$ Endocrinol. 202:43-54. doi:10.1677/JOE-08-0472.

Ma, Y., Ladisa, C., Chang, J. P., Habibi, H. R. (2020a). Multifactorial control of reproductive and growth axis in male goldfish: Influences of GnRH, GnIH and thyroid hormone. Mol Cell Endocrinol. 500:110629. doi:10.1016/j.mce.2019.110629.

Ma, Y., Ladisa, C., Chang, J. P., Habibi, H.R. (2020b). Seasonal related multifactorial control of pituitary gonadotropin and growth hormone in female goldfish: Influences of neuropeptides and thyroid hormone. Front Endocrinol. 11:175. doi:10.3389/fendo.2020.00175.

Mackenzie, D. S. (1982). Stimulation of the thyroid gland of a teleost fish, Gill ichthys mirabilis, by tetrapod pituitary glycoprotein hormones. Comp Biochem Physiol A Comp Physiol. 72:477-482. doi: 10.1016/0300-9629(82)90111-6.

Mackenzie, D.S., Sokolowska, M., Peter, R.E., Breton, B. (1987). Increased gonadotropina levels in goldfish do not result in alterations in circulating thyroid hormone levels. Gen Comp Endocrinol. 67:202-213. doi:10.1016/0016-6480(87)90149-3.

Matta, S.L.P., Vilela, D.A.R., Godinho, H.P., França, L.R. (2002). The goitrogen 6-n-propyl-2thiouracil (PTU) given during testis development increases sertoli and germ cell numbers per cyst in fish: the tilapia (Oreochromis niloticus) model. Endocrinol. 143:970-978. doi:10.1210/endo.143.3.8666.

Mendis-Handagama, S.M.L.C, Siril Ariyaratne, H.B. (2005). Leydig cells, thyroid hormones and steroidogenesis. Indian J Exp Biol. 43:939-62.

Miura, T., Miura, C., Konda, Y., Yamauchi, K. (2002). Spermatogenesis-preventing substance in Japanese eel. Development. 129:2689-2697.

Morais, R.D., Nóbrega, R.H., Gomez-Gonzalez, N.E., Schmidt, R., Bogerd, J., França, L.R., Schulz, R.W. (2013). Thyroid hormone stimulates the proliferation of Sertoli cells and single type A spermatogonia in adult zebrafish (Danio rerio) testis. Endocrinol. 154:4365-4376. doi:10.1210/en.2013-1308.

Moussavi, M., Wlasichuk, M., Chang, J. P., Habibi, H. R. (2012). Seasonal effect of GnIH on gonadotrope functions in the pituitary of goldfish. Mol Cell Endocrinol. 350:53-60. doi:10.1016/j.mce.2011.11.020. 


\section{Thyroid hormones deficiency impairs male germ cell development: a cross talk between hypothalamic-pituitary-thyroid, and - gonadal axes in zebrafish}

Moussavi, M., Wlasichuk, M., Chang, J.P., Habibi, H.R. (2013). Seasonal effect of gonadotrophin inhibitory hormone on gonadotrophin-releasing hormone-induced gonadotroph functions in the goldfish pituitary. J Neuroendocrinol. 25:506-516. doi:10.1111/jne.12024.

Moussavi, M., Wlasichuk, M., Chang, J.P., Habibi, H.R. (2014). Seasonal effects of GnIH on basal and GnRH-induced goldfish somatotrope functions. J Endocrinol. 223:191-202. doi:10.1530/joe-140441.

Mukhi, S., Torres, L., Patiño, R. (2007). Effects of larval-juvenile treatment with perchlorate and cotreatment with thyroxine on zebrafish sex ratios. Gen Comp Endocrinol. 150:486-494. doi: 10.1016/j.ygcen.2006.11.013.

Nelson, E.R., Habibi, H.R. (2006). Molecular characterization and sex-related seasonal expression of thyroid receptor subtypes in goldfish. Mol Cell Endocrinol. 253:83-95. doi:

10.1016/j.mce.2006.05.003.

Nelson, E.R., Habibi, H.R. (2008). Seasonal-related homologous regulation of goldfish liver Estrogen receptor subtypes. Cybium. 32:248-249. doi:10.26028/cybium/2008-322SP-124.

Nelson, E.R., Habibi, H.R. (2009). Thyroid receptor subtypes: Structure and function in fish. Gen Comp Endocrinol. 161:90-96. doi: 10.1016/j.ygcen.2008.09.006.

Nelson, E.R.; Allan, E.R.; Pang, F.Y.; Habibi, H.R. (2010). Thyroid hormone and reproduction: regulation of estrogen receptors in goldfish gonads. Mol Reprod Dev. 77:784-794. doi: 10.1002/mrd.21219.

Nelson, E.R., Allan, E.R., Pang, F.Y., Habibi, H.R. (2011). Auto-regulation of thyroid hormone receptors in the goldfish ovary and testis. Gen Comp Endocrinol. 172:50- 55. doi: 10.1016/j.ygcen.2010.12.017.

Nelson, E.R., Habibi, H.R. (2016). Thyroid hormone regulates vitellogenin by inducing estrogen receptor alpha in the goldfish liver. Mol Cell Endocrinol. 436:259-267. doi: 10.1016/j.mce.2016.08.045.

Nóbrega, R.H., Greebe, C.D., Van De Kant, H., Bogerd, J., França, L.R., Schulz, R.W. (2010). Spermatogonial stem cell niche ad spermatogonial stem cell transplantation in zebrafish. Plos One. 5:e12808. doi:10.1371/journal.pone.0012808.

Orozco, A., Valverde, C.R., Olvera, A., García, C.G. (2012). Iodothyronine deiodinases: a functional and evolutionary perspective. J Endocrinol. 215:207-219. doi:10.1530/JOE-12-0258.

Pankhurst, N.W. (2016). Reproduction and development. In Fish Physiology-Biology of Stress in Fish. (eds. Schreck, C.B., Tort, L., Farrell, A., Brauner, C. San Diego, CA: Academic Press. 295331.

Patiño, R., Wainscott, M.R, Cruzli, E.I., Balakrishnan, S., Mcmurry, C., Blazer, V.S., Anderson, T.A. (2003). Effects of ammonium perchlorate on the reproductive performance and thyroid follicle histology of zebrafish. Environ Toxicol Chem. 22:1115-21. 


\section{Thyroid hormones deficiency impairs male germ cell development: a cross talk between hypothalamic-pituitary-thyroid, and - gonadal axes in zebrafish}

Planas, J.V., Swanson, P., Dickhoff, W.W. (1993). Regulation of testicular steroid production in vitro by gonadotropins (GTH I and GTH II) and cyclic AMP in coho salmon (Oncorhynchus kisutch). Gen Comp Endocrinol. 91:8-24. doi:10.1006/gcen.1993.1099.

Poguet, A.L., Legrand, C., Feng, X., Yen, P.M., Meltzer, P., Samarut, J., Flamant, F. (2003). Microarray analysis of knockout mice identifies cyclin D2 as a possible mediator for the action of thyroid hormone during the postnatal development of the cerebellum. Dev Biol. 254:188-199. doi: 10.1016/s0012-1606(02)00039-8.

Rao, J.N., Liang, J.Y., Chakraborti, P., Feng, P. (2003). Effect of thyroid hormone on the development and gene expression of hormone receptors in rat testes in vivo. J Endocrinol Invest. 26:435-43. doi:10.1007/BF03345199.

Rodrigues, M.S., Fallah, P.H., Zanardini, M., Malafaia, G., Habibi, H.R., Nóbrega, R.H. (2021). Interaction between thyroid hormones and gonadotropin inhibitory hormone in ex vivo culture of zebrafish testis: An approach to study multifactorial control of spermatogenesis. Mol Cell Endocrinol. 532:111331. doi:10.1016/j.mce.2021.111331.

Rojdmark, S., Berg, A., Kallner, G. (1988). Hypothalamic-pituitary-testicular axis in patients with hyperthyroidism. Horm Res. 29:185-90. doi:10.1159/000181000.

Roy, P., Datta, M., Dasgupta, S., Bhattacharya, S. (2000). Gonadotropin releasing hormone stimulates thyroid activity in a freshwater murrel, Channa gachua (Ham.), and Carps, Catla catla (Ham.) and Cirrhinus mrigala (Ham.). Gen Comp Endocrinol. 117:456-463. doi: 10.1006/gcen.1999.7432.

Ruiz De Oña, C., Obregón, M. J., Escobar Del Rey, F., Morreale De Escobar, G. (1988). Developmental changes in rat brain 5h-deiodinase and thyroid hormones during the fetal period: The effects of fetal hypothyroidism and maternal thyroid hormones. Pediatric Research. 24:588-594. doi: 10.1203/00006450-198811000-00010.

Safian, D., Morais, R.D.V.S., Bogerd, J., Schulz, R.W. (2016). Igf binding proteins protect undifferentiated spermatogonia in the zebrafish testis against excessive differentiation. Endocrinol. 157:4423-4433. doi:10.1210/en.2016-1315.

Schulz, R.W., França, L.R., Lareyre, J.J., Legac, F., Chiarini-Garcia, H., Nóbrega, R.H., Miura, T. (2010). Spermatogenesis in fish. Gen Comp Endocrinol. 165:390-411. doi: 10.1016/j.ygcen.2009.02.013.

Sharma, P., Tang, S., Mayer, G.D., Patiño, R. (2016). Effects of thyroid endocrine manipulation on sex-related gene expression and population sex ratios in zebrafish. Gen Comp Endocrinol. 235:38-47. doi:10.1016/j.ygcen.2016.05.028.

Sharma, P., Patiño, R. (2013). Regulation of gonadal sex ratios and pubertal development by the thyroid endocrine system in zebrafish. Gen Comp Endocrinol. 184:11-119. doi:10.1016/j.ygcen.2012.12.018.

Swapna, I., Rajasekhar, M., Supriya, A., Raghuveer, K., Sreenivasulu, G., Rasheeda, M.K., Majumdar, K.C., Hagawa, H., Tanaka, H., Dutta-Gupta, A., Senthilkumaran, B. (2006). Thioureainduced thyroid hormone depletion impairs testicular recrudescence in the air-breathing catfish, 


\section{Thyroid hormones deficiency impairs male germ cell development: a cross talk between hypothalamic-pituitary-thyroid, and - gonadal axes in zebrafish}

Clarias gariepinus. Comp Biochem Physiol A Mol Integr Physiol. 144:1-10. doi: 10.1016/j.cbpa.2006.01.017.

Swapna, I., Senthilkumaran, B. (2007). Thyroid hormones modulate the hypothalamo-hypophysealgonadal axis in teleosts: molecular insights. Fish Physiol Biochem. 33:335-45. doi:10.1007/s10695007-9165-2.

Teerds, K.J., De Rooji, D.G., De Jong, F.H., Van Haaster, L.H. (1998). Development of the adulttype Leydig cell population in the rat is affected by neonatal thyroid hormone levels. Biol Reprod. 59:344-350. doi:10.1095/biolreprod59.2.344.

Tovo-Neto, A., Rodrigues, M.S., Habibi, H. R., Nóbrega, R. H. (2018). Thyroid hormone actions on male reproductive system of teleost fish. Gen Comp Endocrinol. 265:230-236. doi: 10.1016/j.ygcen.2018.04.023.

Tovo-Neto, A., Martinez, E. R. M., Melo, A. G., Doretto, L. B., Butzge, A. J., Rodrigues, M. S., Nakajima, R. T., Habibi, H. R., Nóbrega, R. H. (2020). Cortisol directly stimulates spermatogonial differentiation, meiosis, and spermiogenesis in zebrafish (Danio rerio) testicular explants. Biomolecules. 10:429. doi:10.3390/biom10030429.

Tousson, E., Ali, E.M., Ibrahim, W., Mansour, M.A. (2011). Proliferating cell nuclear antigen as a molecular biomarker for spermatogenesis in PTU- induced hypothyroidism of rats. Reprod Sci. 18:679-86. doi:10.1177/1933719110395401.

Trudeau, V.L., Murthy, C.K., Habibi, H. R., Sloley, B. D., Peter, R .E. (1993). Effects of sex steroid treatments on gonadotropin-releasing hormone-stimulated gonadotropin secretion from the goldfish pituitary. Biol Reprod. 48:300-7. doi:10.1095/biolreprod48.2.300.

Tsutsui, K., Son, Y. L., Kiyohara, M., Miyata, I. (2017). Discovery of GnIH and its role in hypothyroidism-induced delayed puberty. Endocrinol. 159:62-68. doi:10.1210/en.2017-00300.

ValadareS, N.F., Polikarpov, I., Garratt, R.C. (2008). Ligand induced interaction of thyroid hormone receptor beta with its coregulators. J Steroid Biochem Mol Biol. 112:205-12. doi:10.1016/j.jsbmb.2008.10.006.

Van Der Ven, L.T.M., Van Den Brandhof, E.-J., Vos, J.H., Power, D.M., Wester, P.W. (2006). Effects of the antithyroid agent propylthiouracil in a partial life cycle assay with zebrafish. Environ Sci Technol. 40:74-81. doi:10.1021/es050972c.

Xie, X., Nóbrega, R., Pšenička, M. (2020). Spermatogonial stem cells in fish: characterization, isolation, enrichment, and recent advances of in vitro culture systems. Biomolecules.10:644. doi: 10.3390/biom10040644.

Wagner, M.S., Wajner, S.M., Maia, A.L. (2008). The role of thyroid hormone in testicular development and function. J Endocrinol. 199:351-365. doi:10.1677/JOE-08-0218.

Wagner, M.S., Wajner, S.M., Maia, A.L. (2009). Is there a role for thyroid hormone on spermatogenesis? Microsc Res Tech. 72:796-808. doi:10.1002/jemt.20759. 
bioRxiv preprint doi: $h$ ttps://doi.org/10.1101/2022.01.30.478377; this version posted January 30, 2022. The copyright holder for this preprint (which was not certified by peer review) is the author/funder, who has granted bioRxiv a license to display the preprint in perpetuity. It is made available under aCC-BY-NC-ND 4.0 International license.

\section{Thyroid hormones deficiency impairs male germ cell development: a cross talk between hypothalamic-pituitary-thyroid, and - gonadal axes in zebrafish}

982

983

984

985

986

987

988

989

990

991

992

993

994

995

996

997

998

999

1000

1001

1002

1003

1004

1005

Wajner, S.M., Wagner, M.S., Maia, A.L. (2009). Clinical implications of altered thyroid status in male testicular function. Arq Bras de Endocrinol Metab. 53:976-982. doi: 10.1590/S000427302009000800011.

Wang, D.S., Baowei, J., Chongjiang, H., Xigui, H., Zhihao, L., Christopher, H.K.C. (2008). Discovery of a gonad-specific IGF subtype in teleost. Biochemical and Biophysical Research Communications. 367:336-341. doi:10.1016/j.bbrc.2007.12.136.

Weng, Q., Saita, E., Watanabe, G., Takahashi, S., Sedqyar, M., Suzuki, A. K., Taneda, S., Taya, K. (2007). Effect of methimazole-induced hypothyroidism on adrenal and gonadal functions in male Japanese quail (Coturnix japonica). J Reprod Dev. 53-1335-41. doi:10.1262/jrd.19081.

Yan, Y.L., Desvignes, T., Bremiller, R., Wilson, C., Dillon, D., High, S., Draper, B., Buck, C.L., Postlethwait, J. (2017). Gonadal soma controls ovarian follicle proliferation through Gsdf in zebrafish. Dev Dyn. 246:925-945. doi:10.1002/dvdy.24579.

Yano, A., Suzuki, K., Yoshizaki, G. (2008). Flow-cytometric isolation of testicular germ cells from rainbow trout (Oncorhynchus mykiss) carrying the green fluorescent protein gene driven by trout vasa regulatory regions. Biol Reprod. 78:151-158. doi:10.1095/biolreprod.107.064667.

Yoshiura, Y., Sohn, Y. C., Munakata, A., Kobayashi, M., Aida, K. (1999). Molecular cloning of the cDNA encoding the $\beta$ subunit of thyrotropin and regulation of its gene expression by thyroid hormones in the goldfish, Carassius auratus. Fish Physiology and Biochemistry. 21:201-210. doi: 10.1016/s0303-7207(01)00392-6.

Zhang, Y., Li, S., Liu, Y., Lu, D., Chen, H., Huang, X., Liu, X., Meng, Z. Lin, H., Cheng, C.H.R. (2010). Structural diversity of the gnih/gnih receptor system in teleost: Its involvement in early development and the negative control of LH release. Peptides. 31:1034-1043. doi:

10.1016/j.peptides.2010.03.003. 
C Methimazole $(1 \mathrm{mM})+\mathrm{T} 4(100 \mu \mathrm{g} / \mathrm{L})$
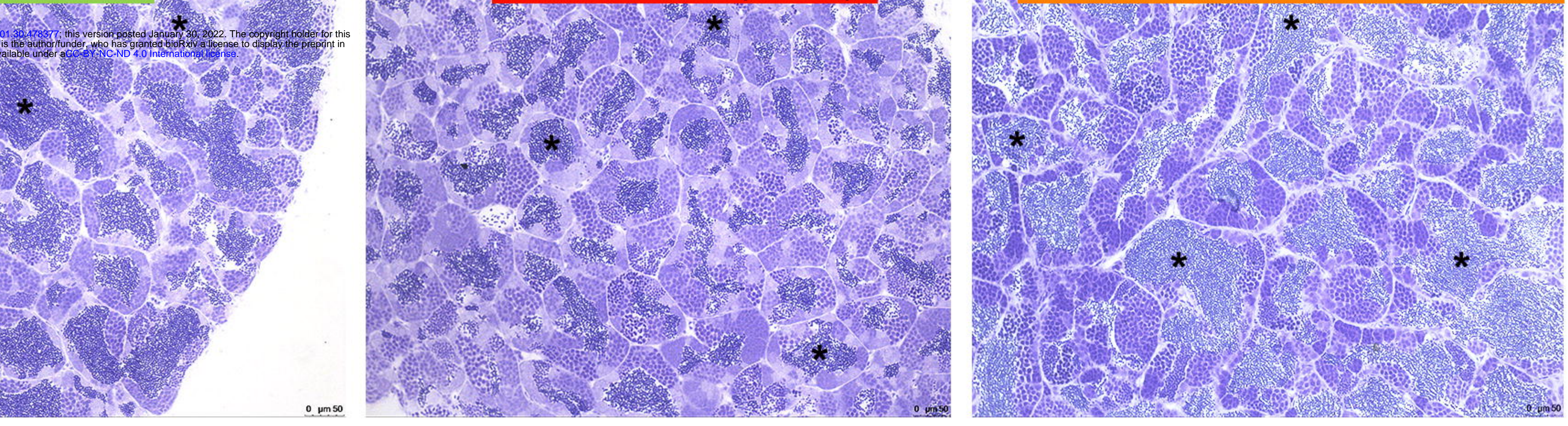

D

ㅇ. unsso

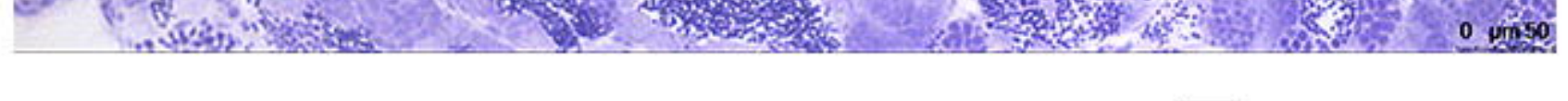

\section{E}

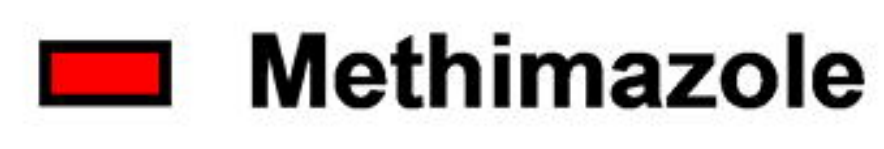

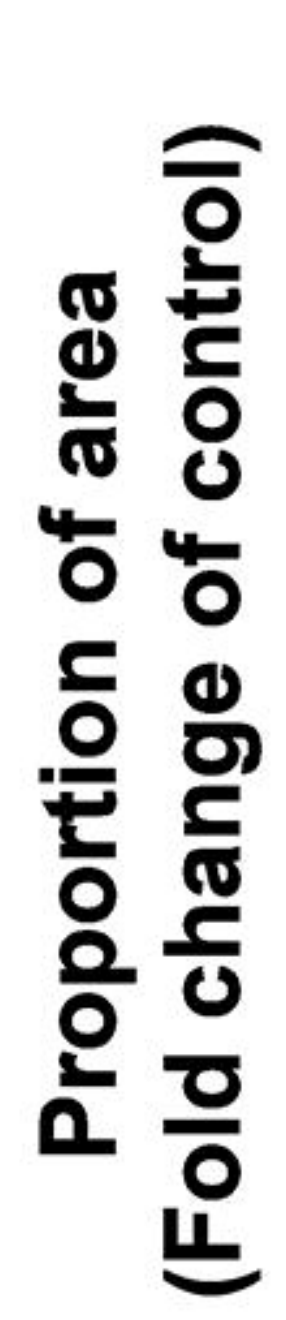

$\square$ Methimazole + T4

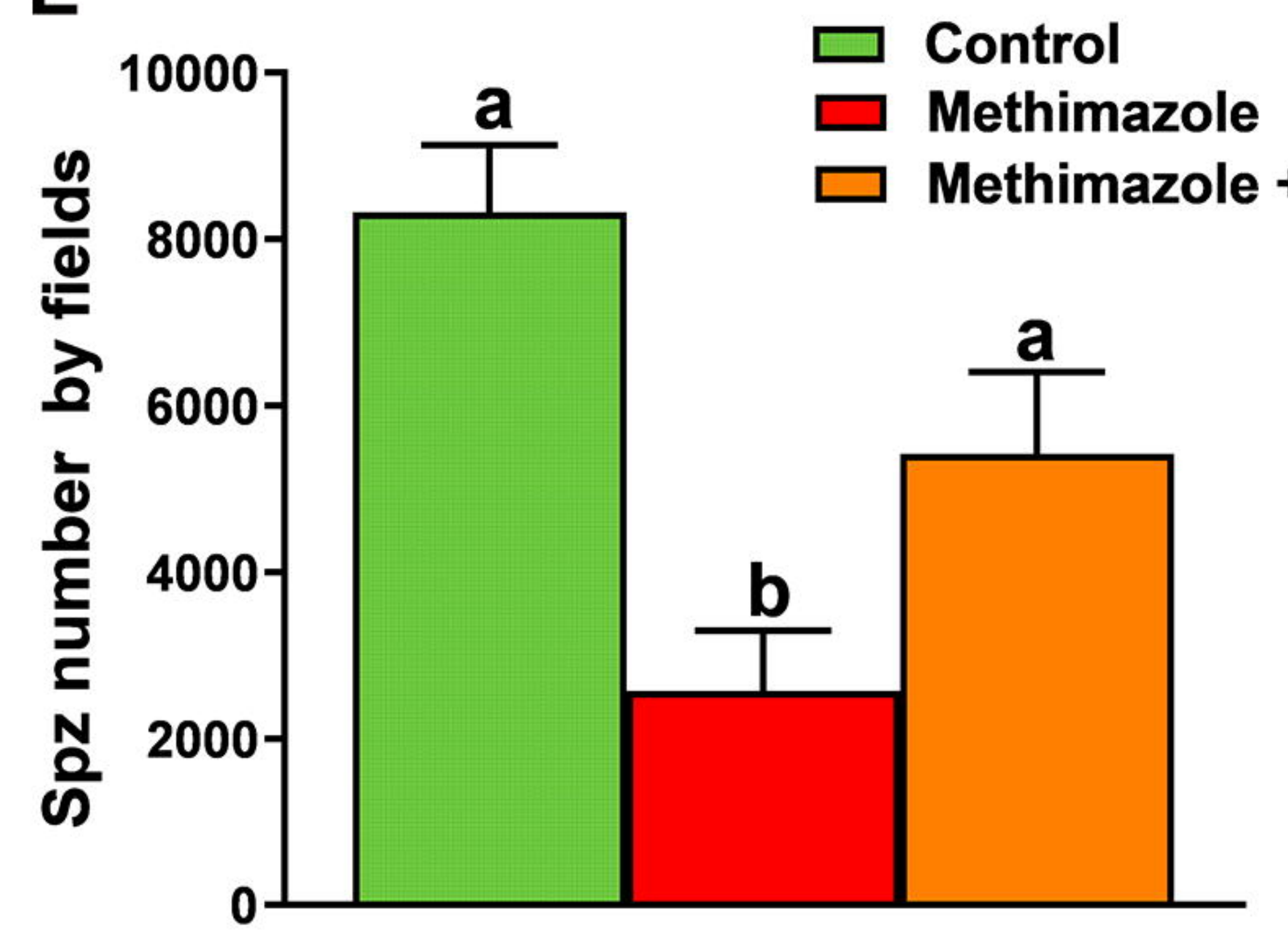

And $^{*}$
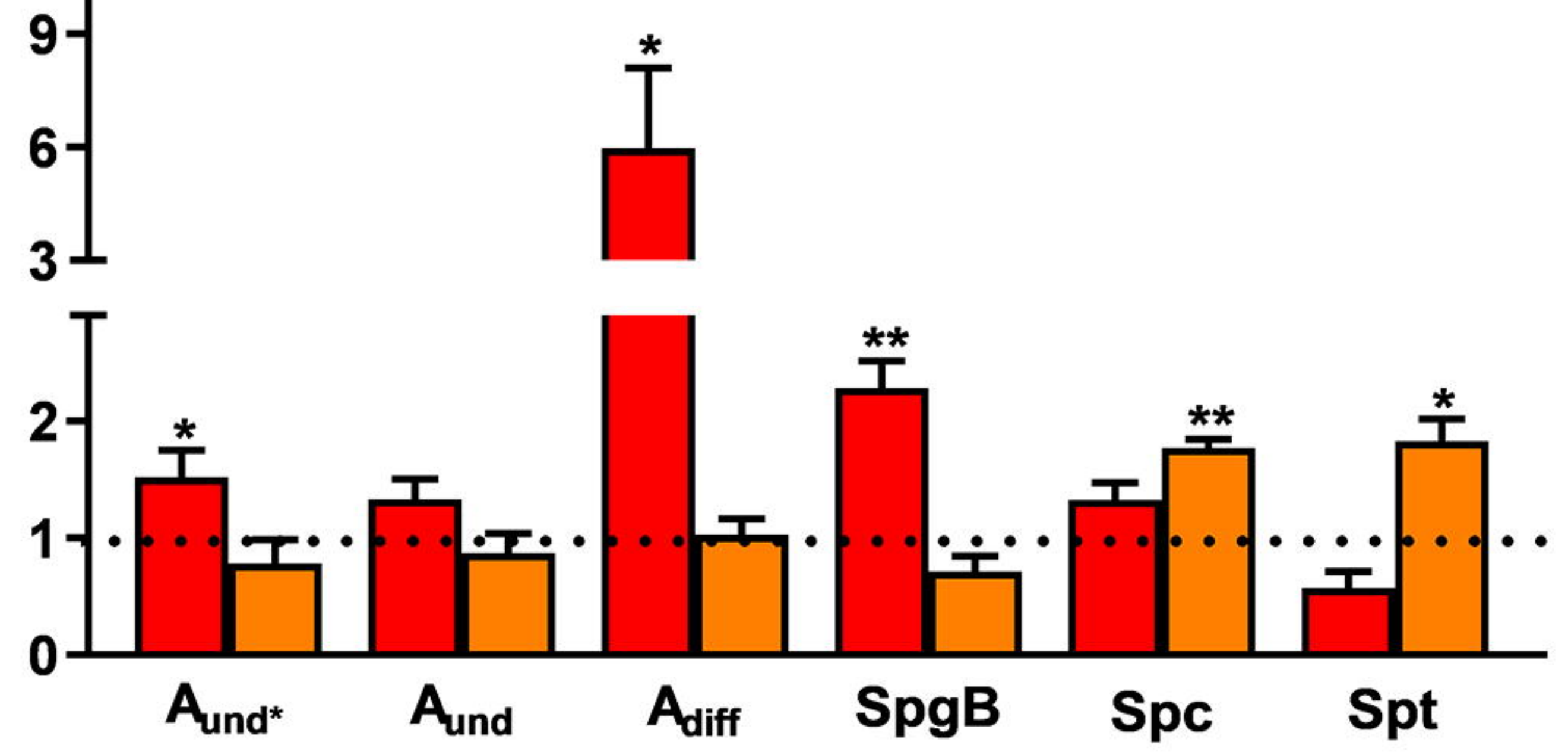
A

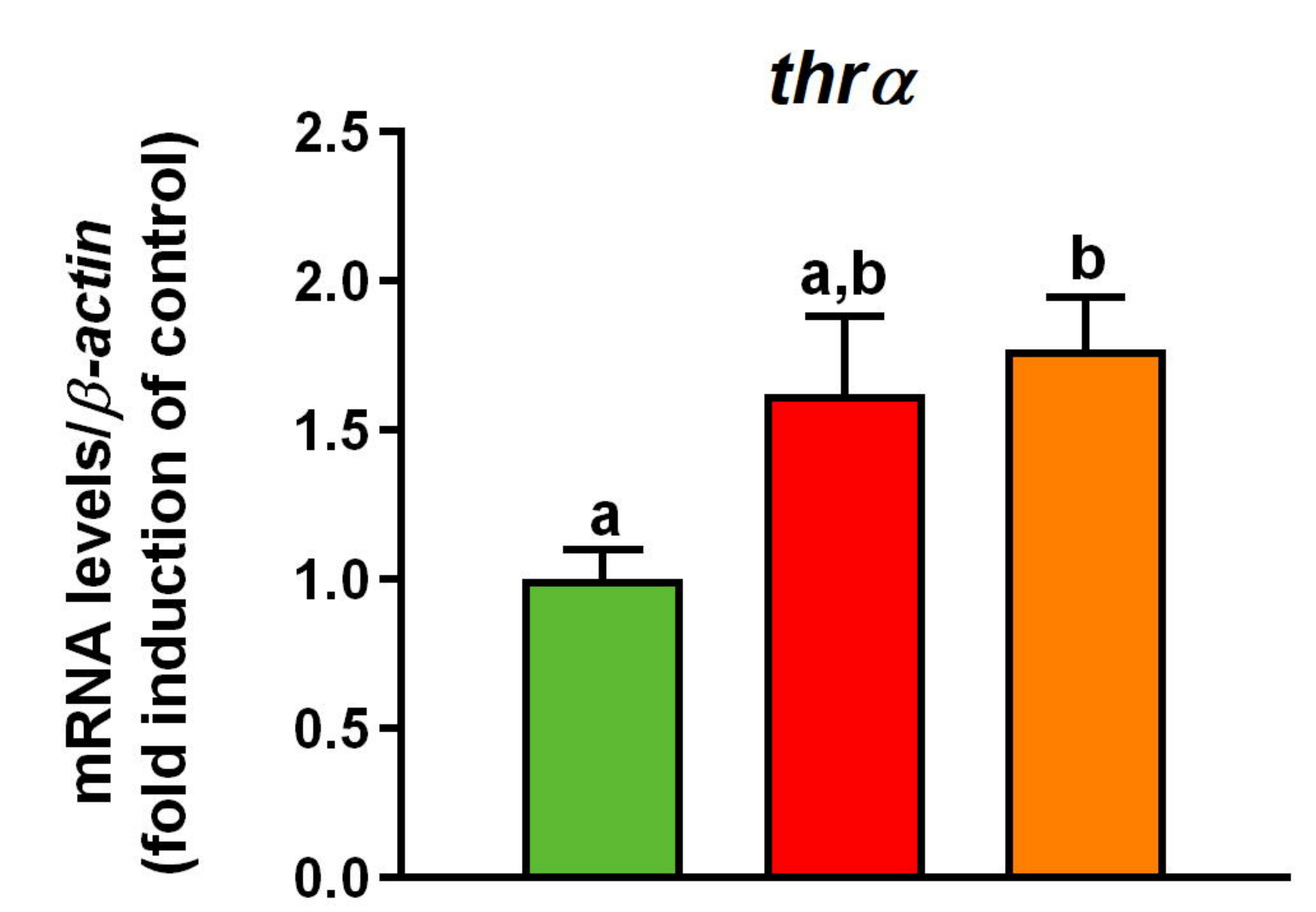

E

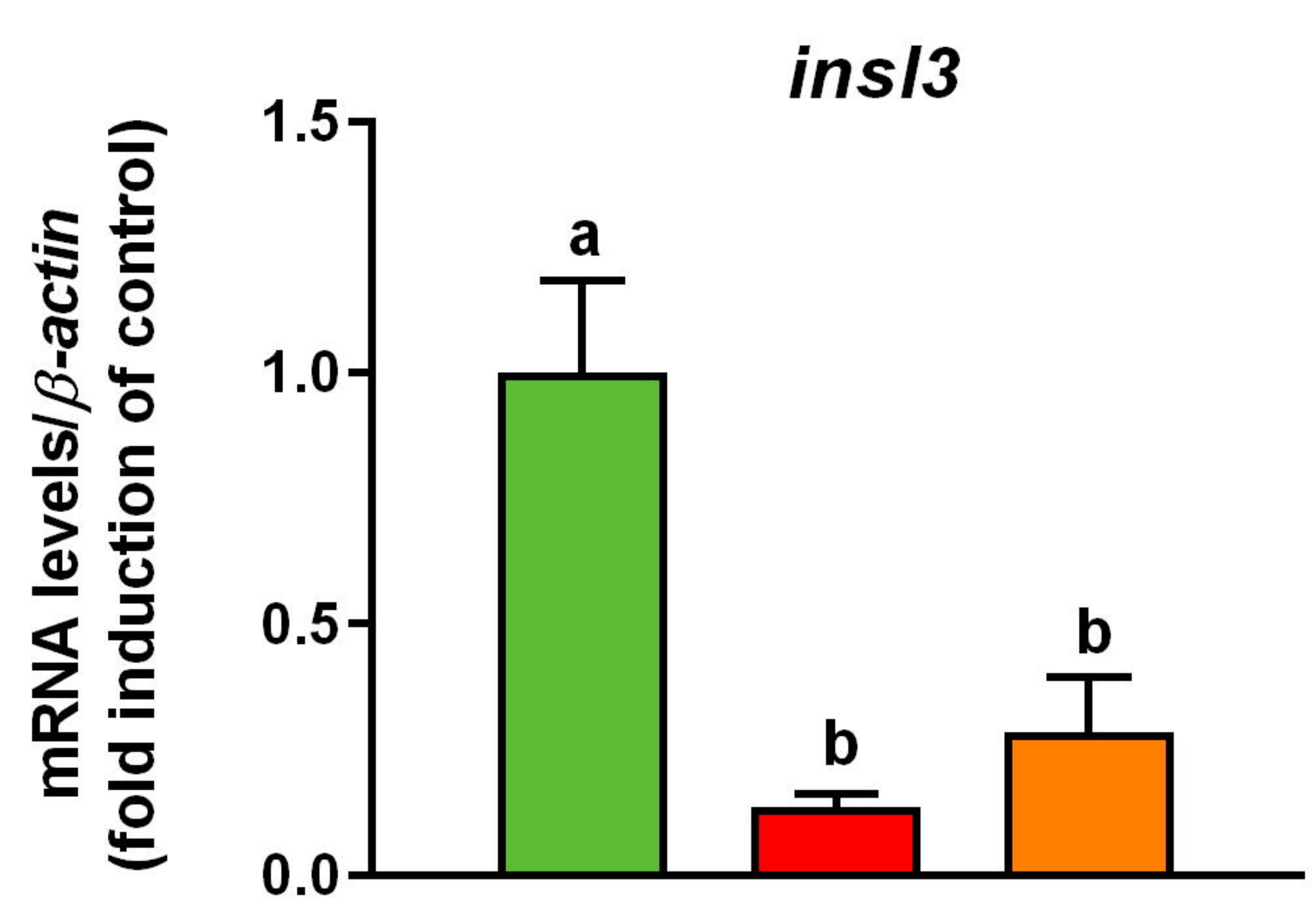

।

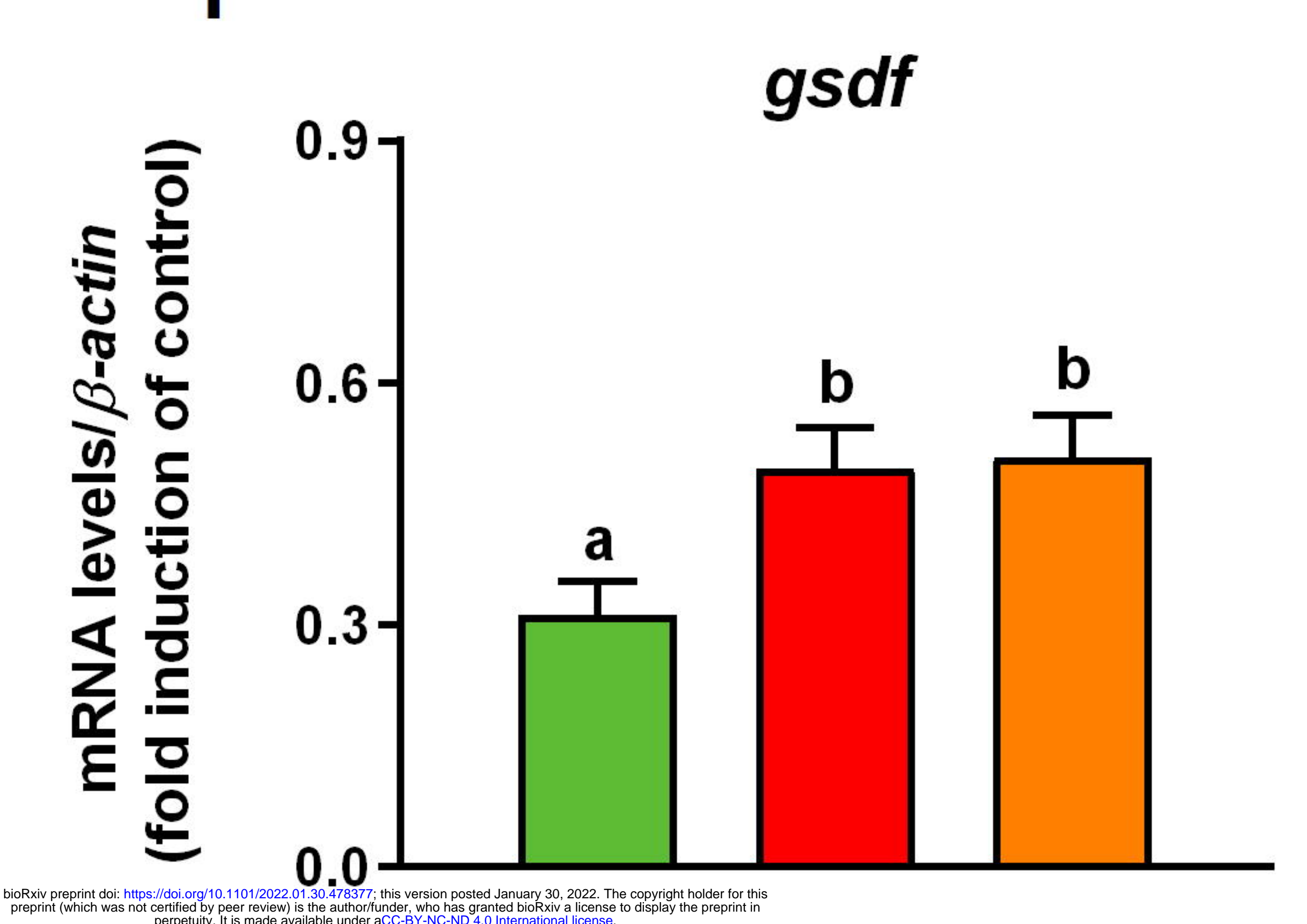

B

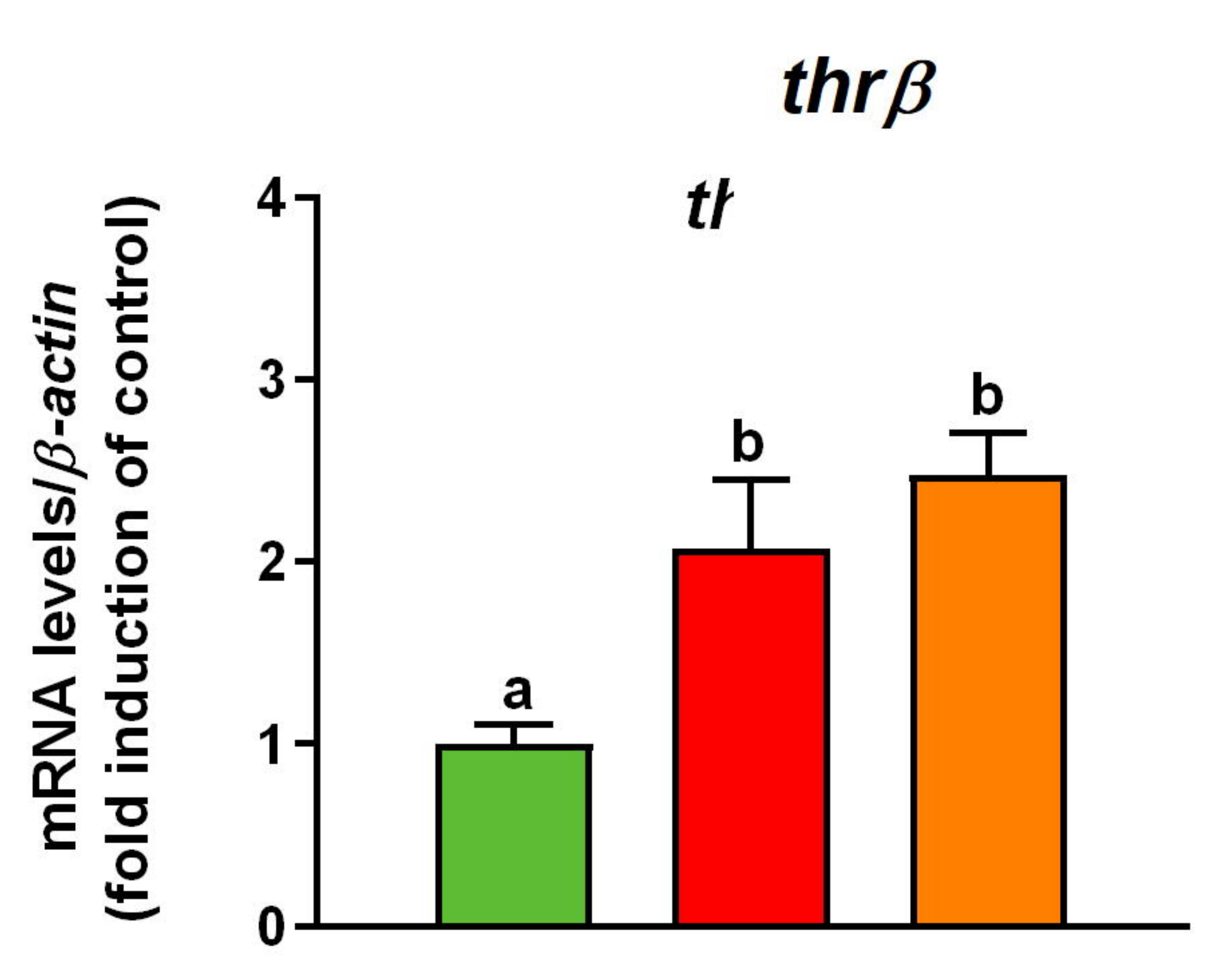

F

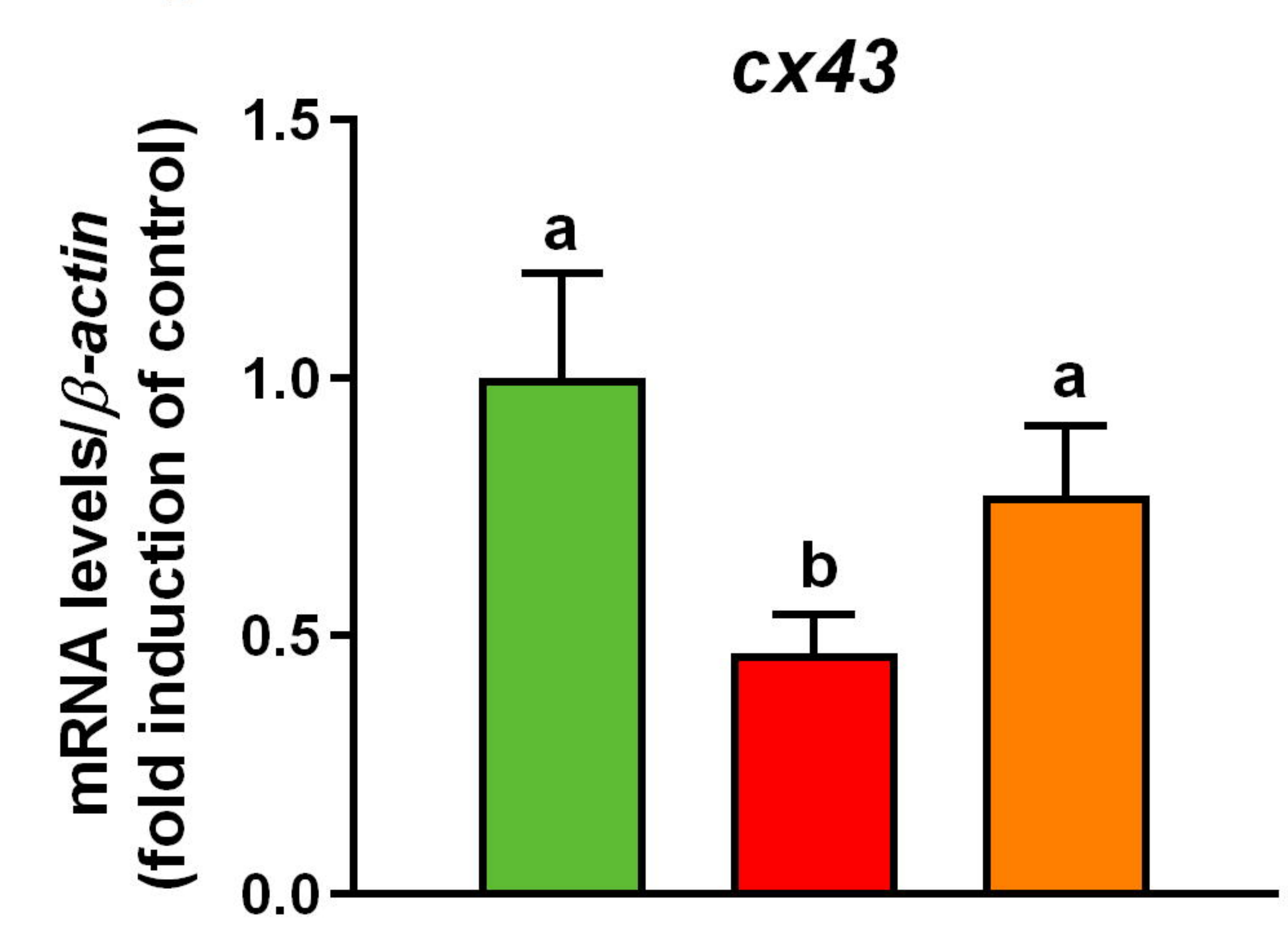

J

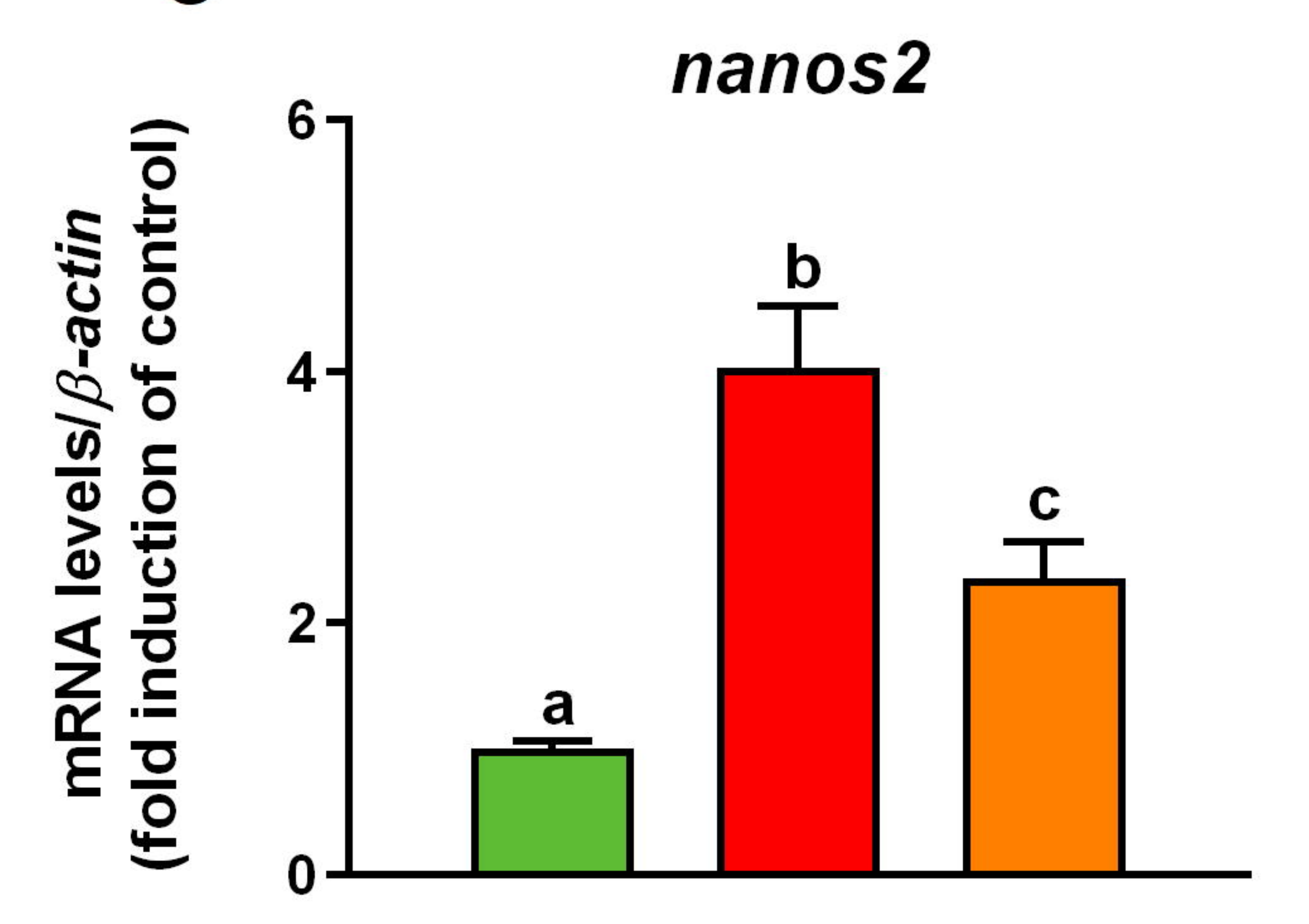

C

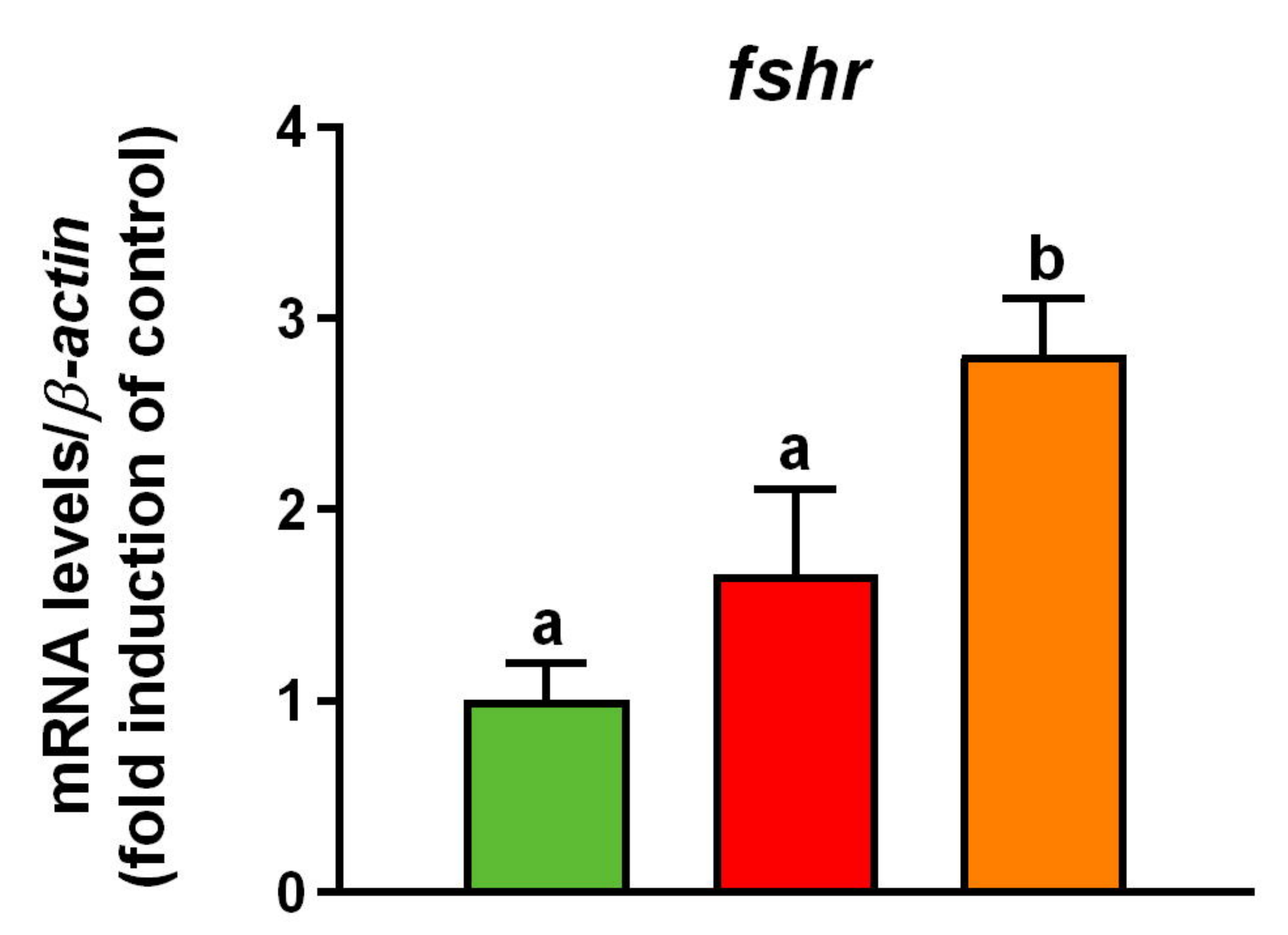

G

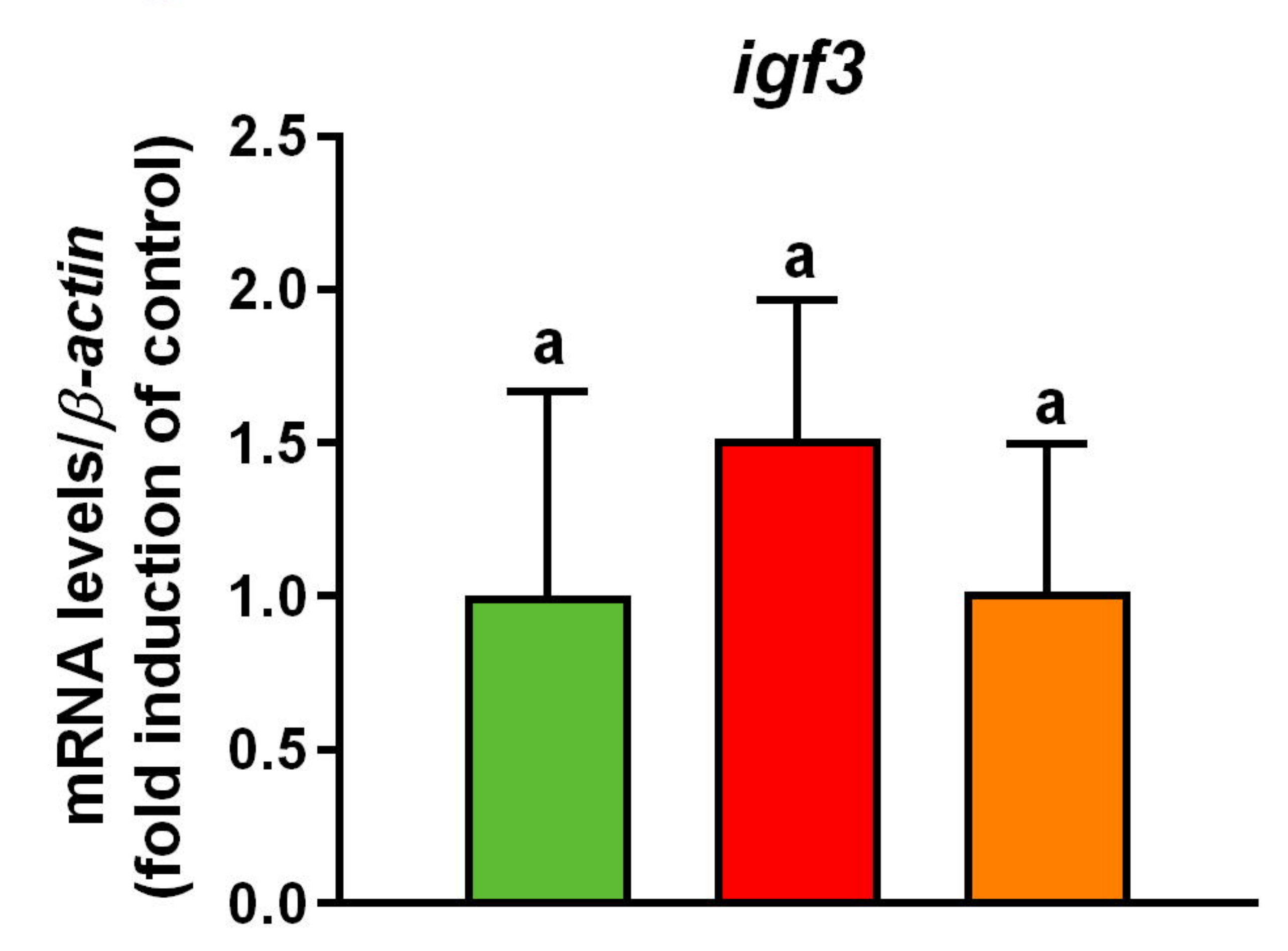

K

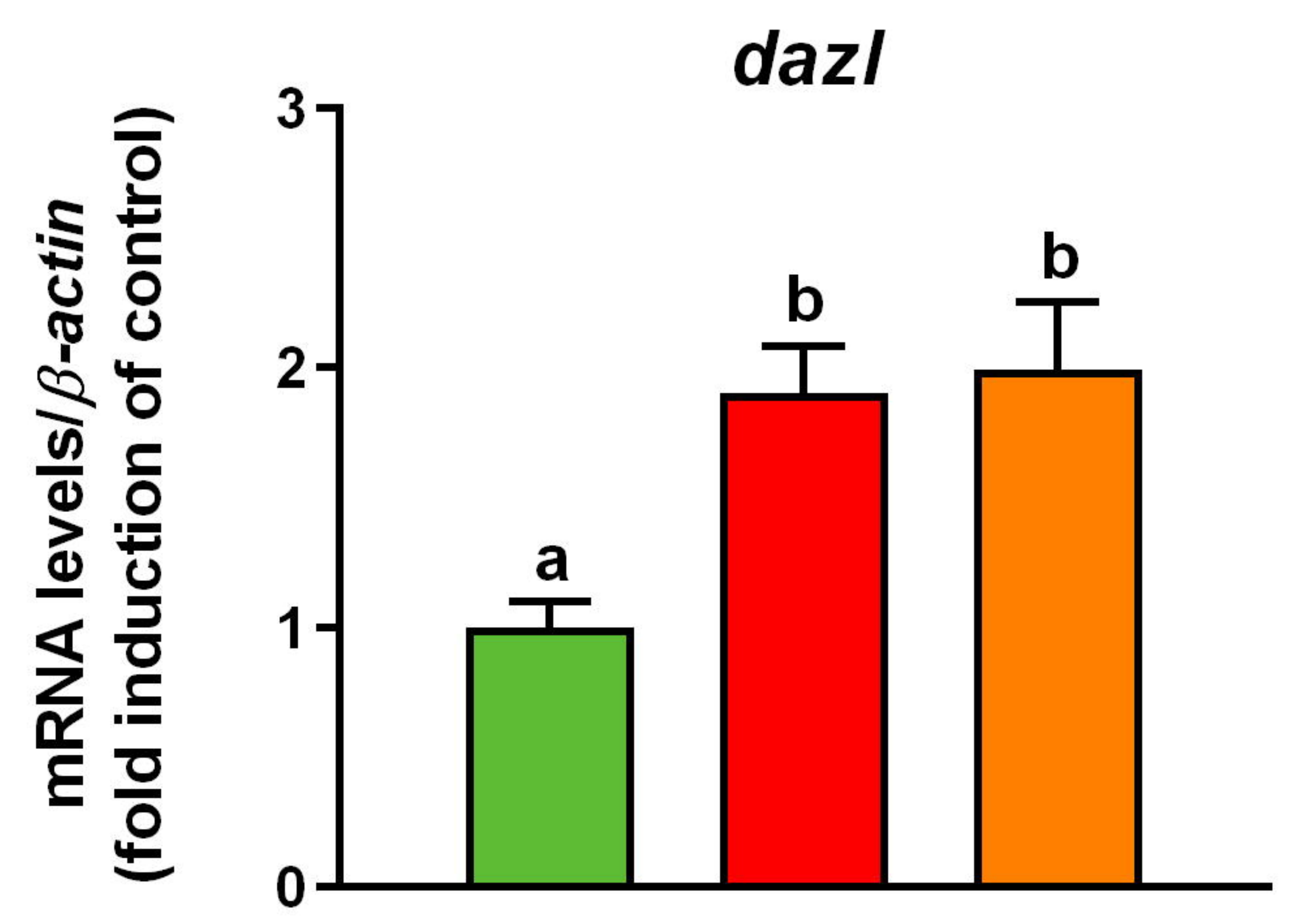

D

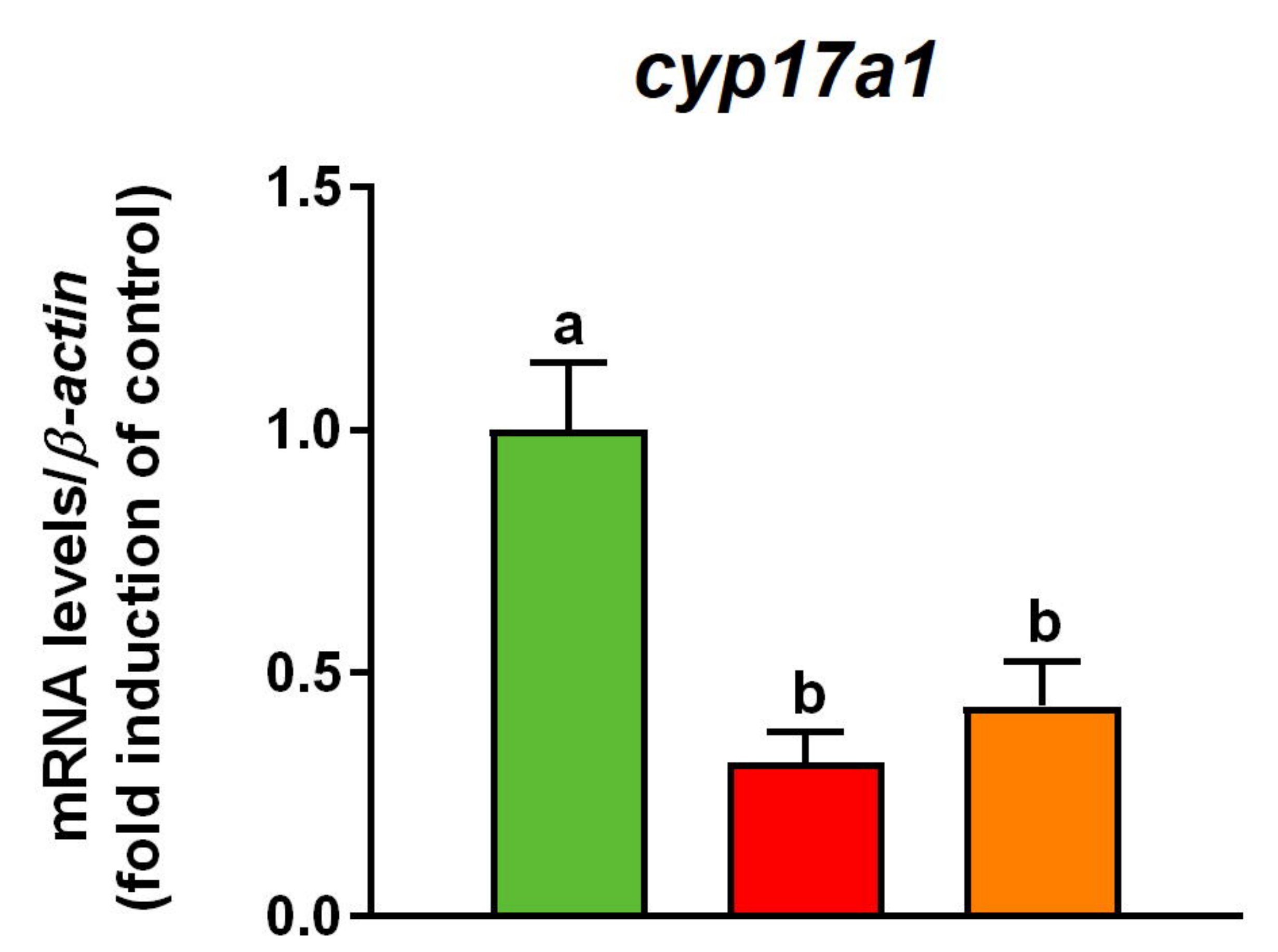

$\mathrm{H}$

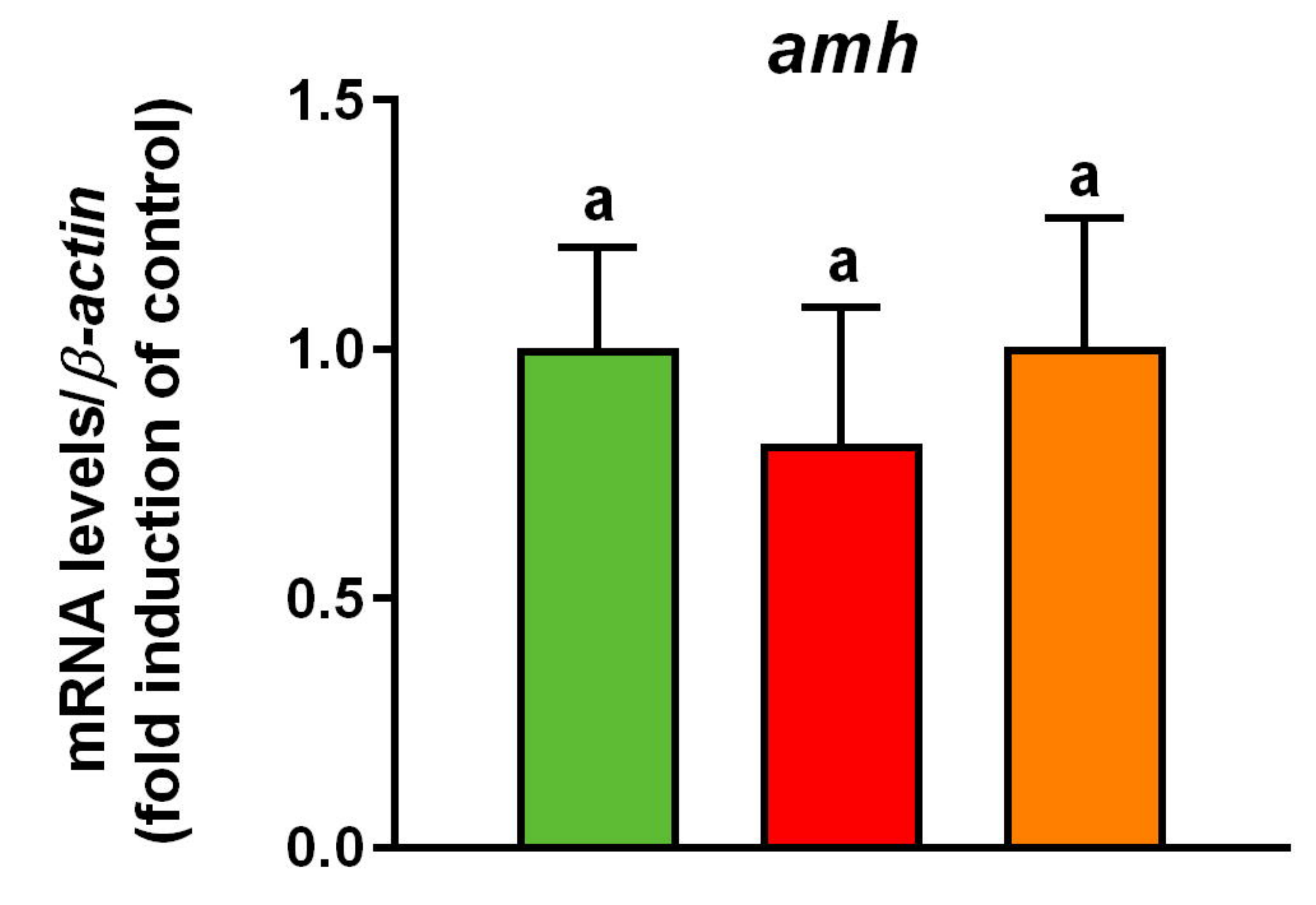

L

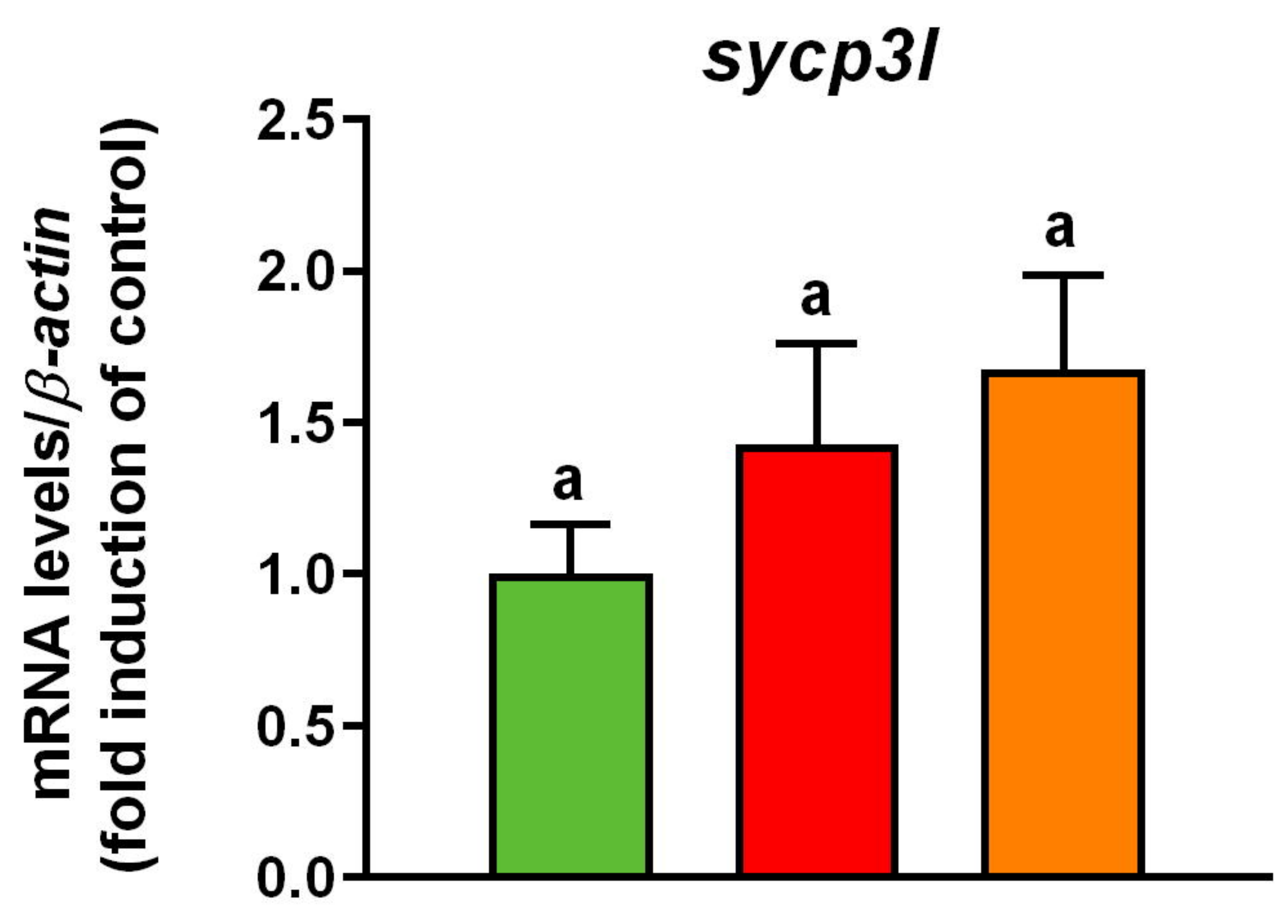

M

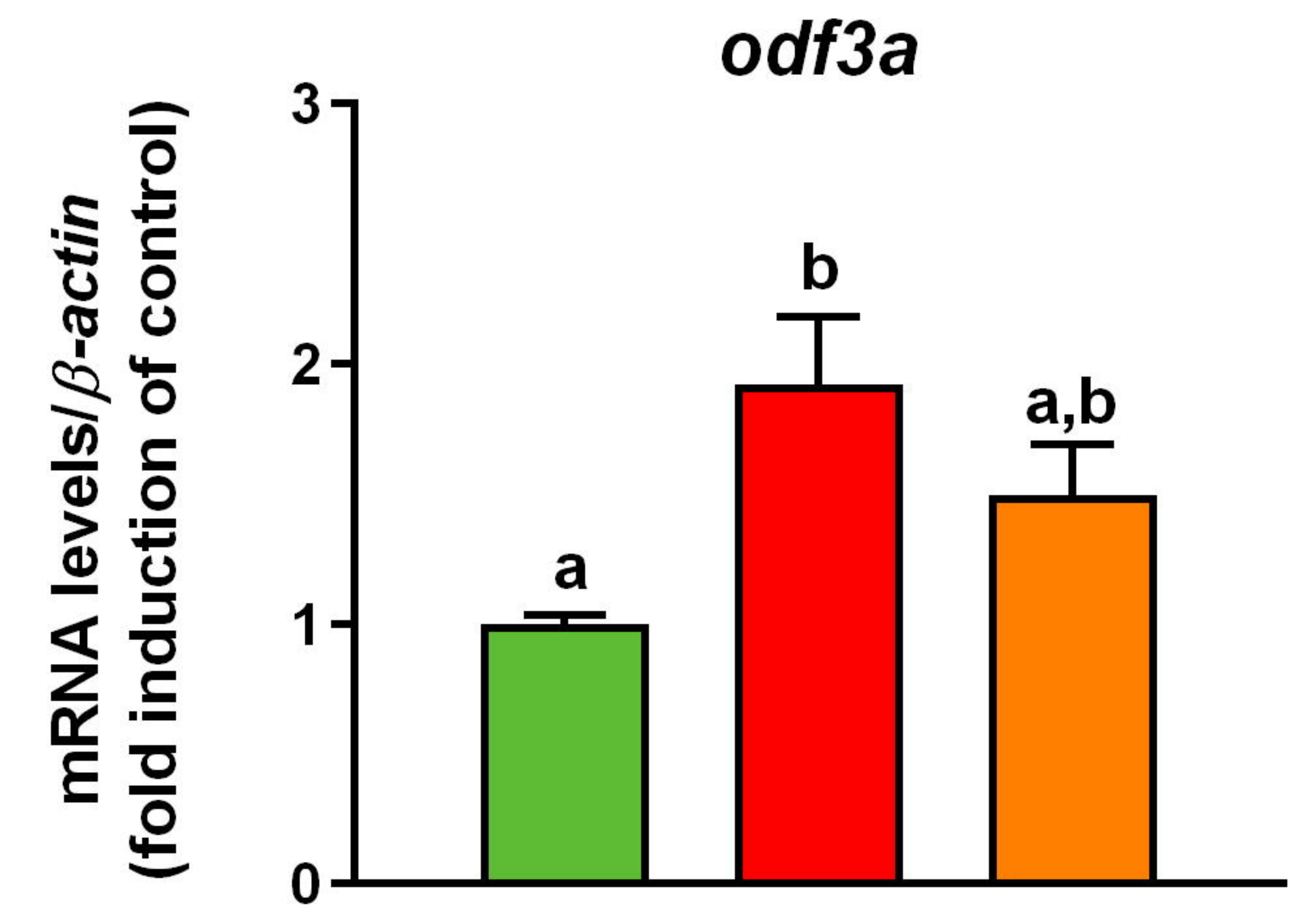




\section{B. Experiment 2}

Control Methimazole (1 mM)
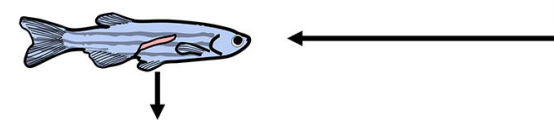

c

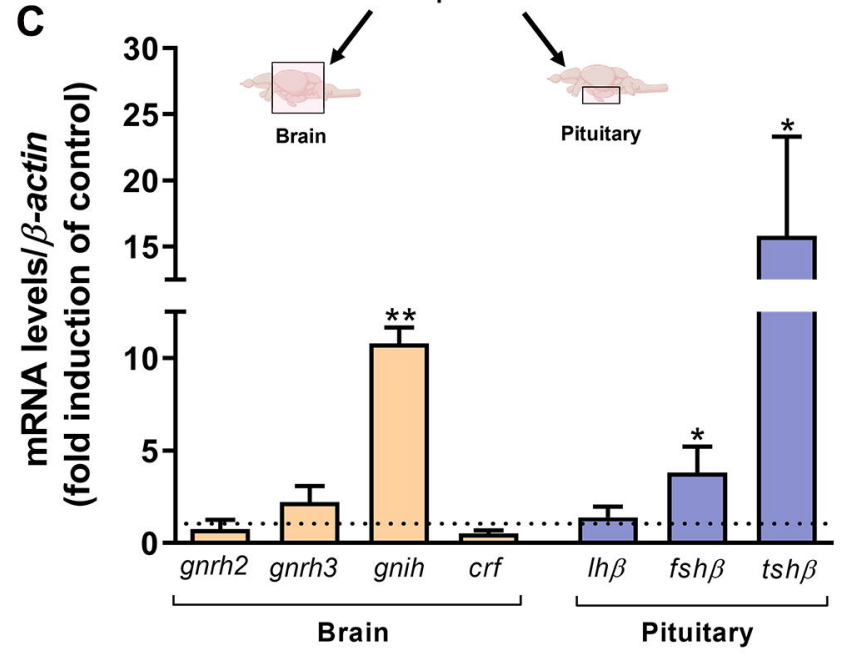

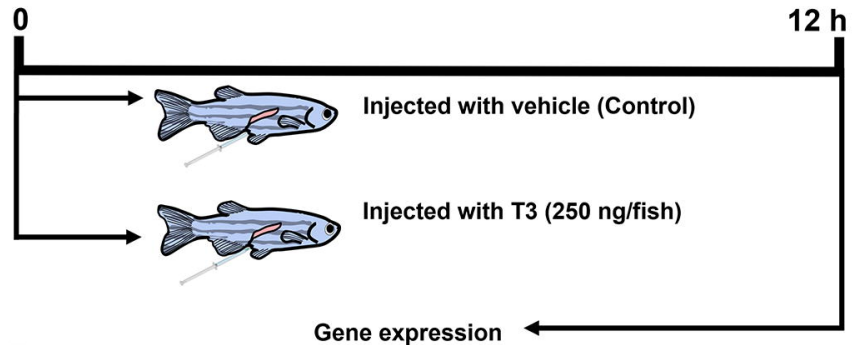

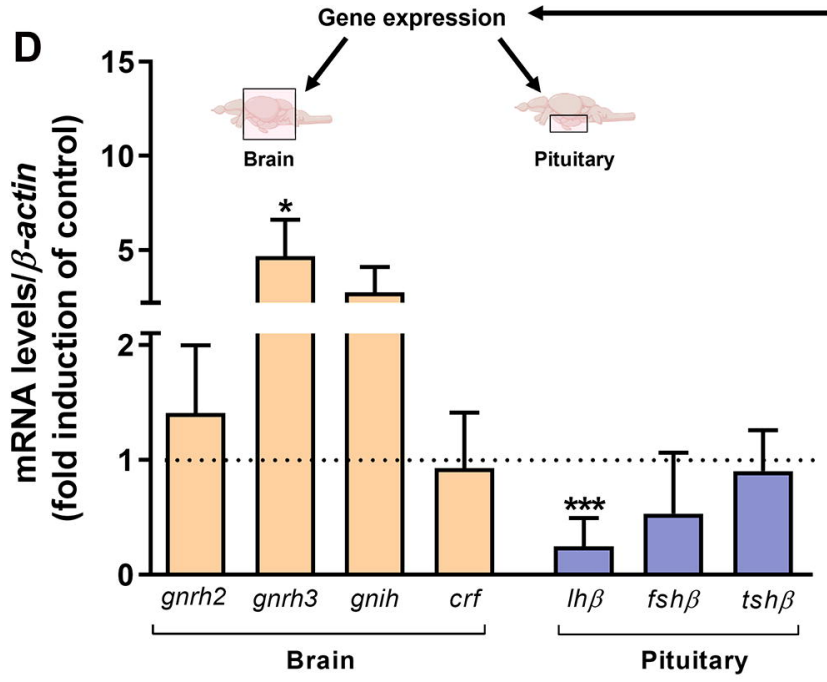




\section{A. Experimental design}

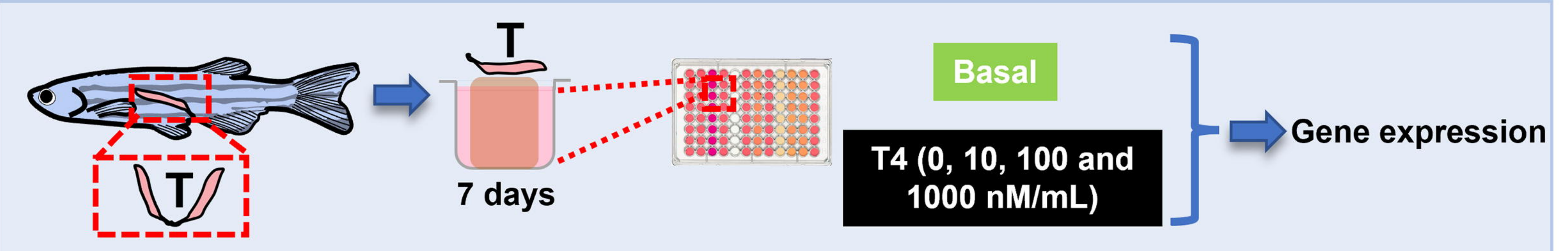

B

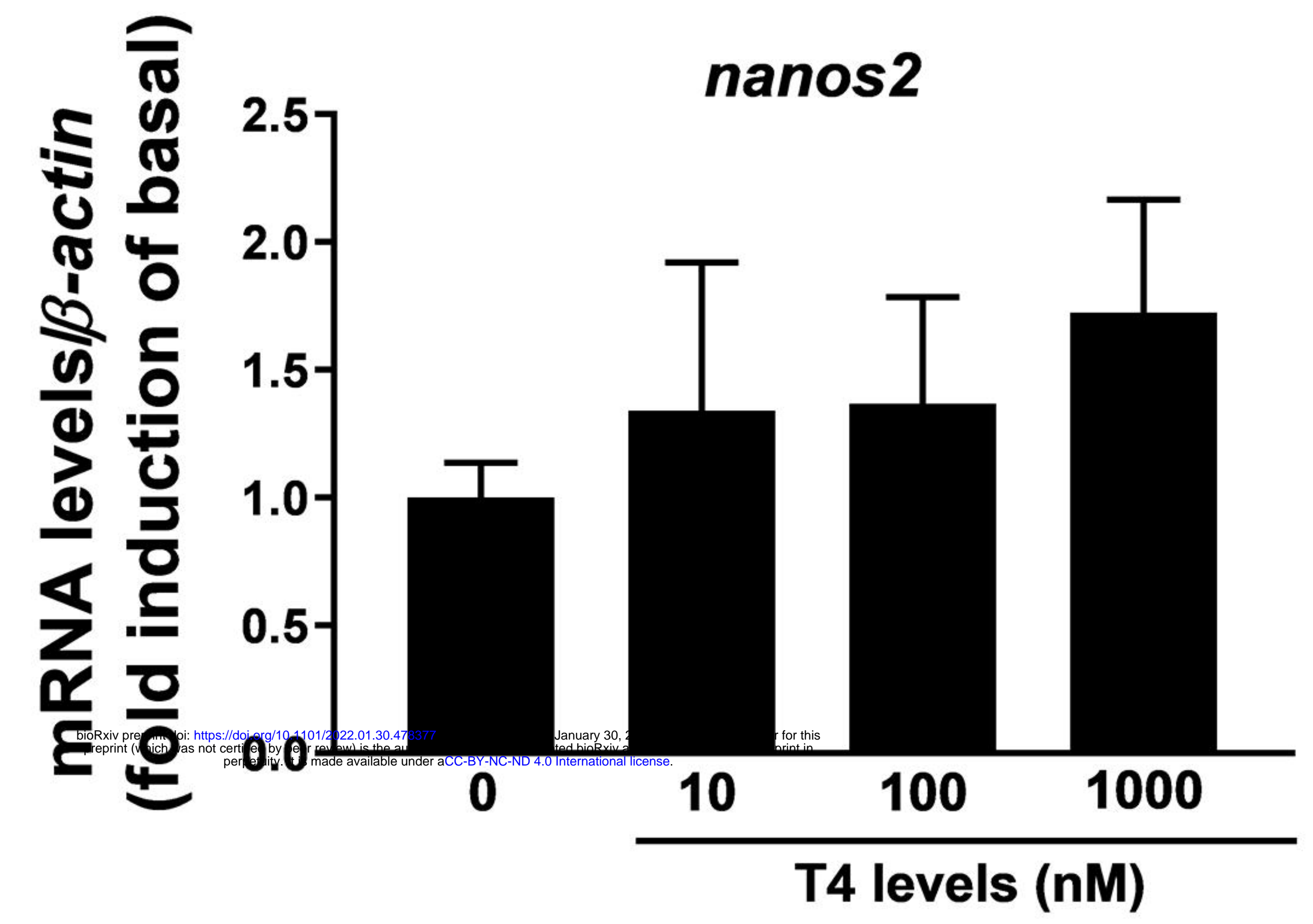

D

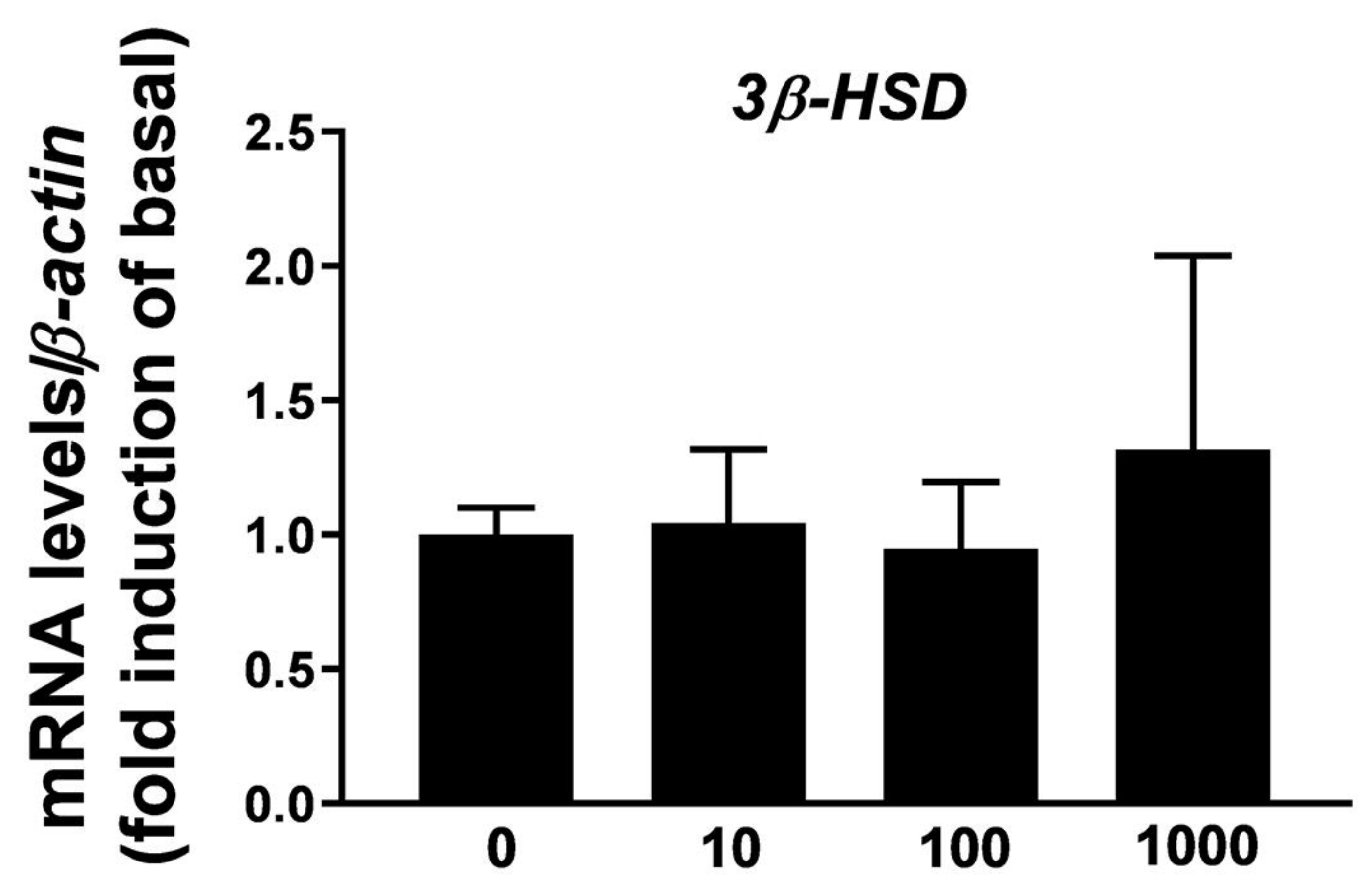

C

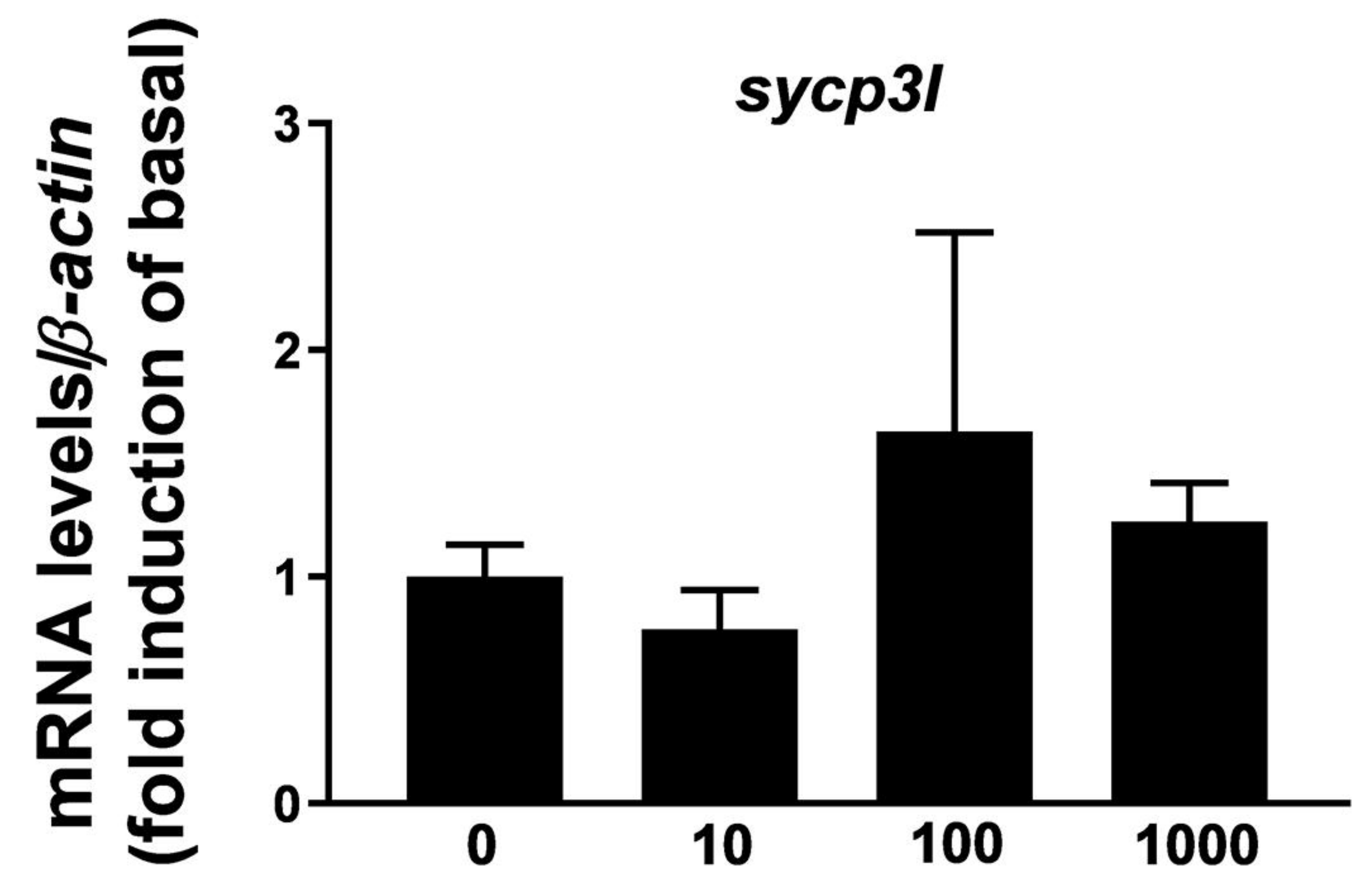

E

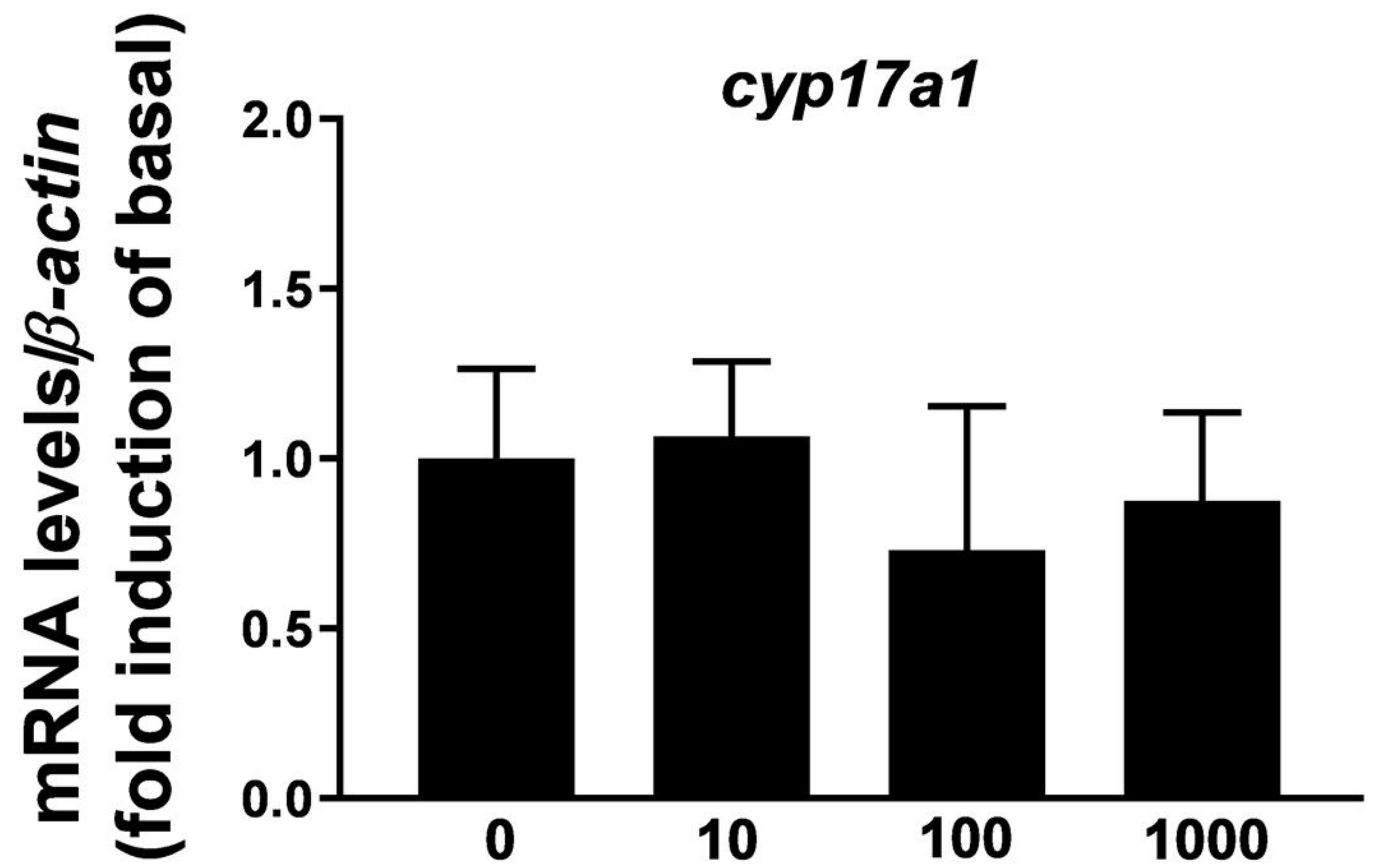

